\title{
Technical Report on Material Selection and Processing Guidelines for BWR Coolant Pressure Boundary Piping
}

\section{Draft Report}

W. S. Hazelton

Office of

Nuclear Reactor Regulation

U.S. Nuclear Regulatory Commission

$$
4+20
$$

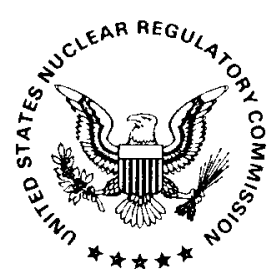




\section{DISCLAIMER}

This report was prepared as an account of work sponsored by an agency of the United States Government. Neither the United States Government nor any agency Thereof, nor any of their employees, makes any warranty, express or implied, or assumes any legal liability or responsibility for the accuracy, completeness, or usefulness of any information, apparatus, product, or process disclosed, or represents that its use would not infringe privately owned rights. Reference herein to any specific commercial product, process, or service by trade name, trademark, manufacturer, or otherwise does not necessarily constitute or imply its endorsement, recommendation, or favoring by the United States Government or any agency thereof. The views and opinions of authors expressed herein do not necessarily state or reflect those of the United States Government or any agency thereof. 


\section{DISCLAIMER}

Portions of this document may be illegible in electronic image products. Images are produced from the best available original document. 


\section{NOTICE}

\section{Availability of Reference Materials Cited in NRC Publications}

Most documents cited in NRC publications will be available from one of the following sources:

1. The NRC Public Document Room, 1717 H Street, N.W.

Washington, DC 20555

2. The Superintendent of Documents, U.S. Government Printing Office, Post Office Box 37082 , Washington, DC 20013-7082

3. The National Technical Information Service, Springfield, VA 22161

Although the listing that follows represents the majority of documents cited in NRC publications, it is not intended to be exhaustive.

Referenced documents available for inspection and copying for a fee from the NRC Public Document Room include NRC correspondence and internal NRC memoranda; NRC Office of Inspection and Enforcement bulletins, circulars, information notices, inspection and investigation notices; Licensee Event Reports; vendor reports and correspondence; Commission papers; and applicant and licensee documents and correspondence.

The following documents in the NUREG series are available for purchase from the GPO Sales Program: formal NRC staff and contractor reports, NRC-sponsored conference proceedings, and NRC booklets and brochures. Also available are Regulatory Guides, NRC regulations in the Code of Federal Regulations, and Nuclear Regulatory Commission Issuances.

Documents available from the National Technical Information Service include NUREG series reports and technical reports prepared by other federal agencies and reports prepared by the Atomic Energy Commission, forerunner agency to the Nuclear Regulatory Commission.

Documents available from public and special technical libraries include all open literature items, such as books, journal and periodical articles, and transactions. Federal Register notices, federal and state legislation, and congressional reports can usually be obtained from these libraries.

Documents such as theses, dissertations, foreign reports and translations, and non-NRC conierence proceedings are available for purchase from the organization sponsoring the publication cited.

Single copies of NRC draft reports are available free, to the extent of supply, upon written request to the Division of Technical Information and Document Control, U.S. Nuclear Regulator'y Commission, Washington, DC 20555.

Copies of industry codes and standards used in a substantive manner in the NRC regulatory process are maintained at the NRC Library, 7920 Norfolk Avenue, Bethesda, Maryland, and are available there for reference use by the public. Codes and standards are usually copyrighted and may be purchased from the originating organization or, if they are American National Standards, from the American National Standards Institute, 1430 Broadway, New York, NY 10018. 
Rev. 2

\section{Technical Report on Material for BWR Coolant Pressure Boundary Piping} Selection and Processing Guidelines

Draft Report

NUREG--0313-Rev . 2

TI86 901552

Manuscript Completed: May 1986

Date Published: June 1986

W. S. Hazelton

Division of BWR Licensing

Office of Nuclear Reactor Regulation

U.S. Nuclear Regulatory Commission

Washington, D.C. 20555

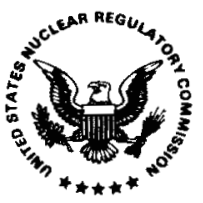




\section{ABSTRACT}

This report updates and supersedes the technical positions NRC established in NUREG-0313, "Technical Report on Material Selection and Processing Guidelines for BWR Coolant Pressure Boundary Piping," published in July 1977, and its subsequent revision published in July 1980.

This report sets forth the NRC staff's revised acceptable methods to control the intergranular stress corrosion cracking susceptibility of BWR ASME Code Class 1,2 , and 3 pressure boundary piping and safe ends. For piping that does not fully comply with the material selection, testing, and processing guideline combinations of this document, varying degrees of augmented inservice inspection will be required, pursuant to 10 CFR $50.55 \mathrm{a}(\mathrm{g})(6)(\mathrm{i} i)^{*}$. This revision also includes guidance regarding crack evaluation and weld overlay repair methods for long term operation or for continuing interim operation of plants until a more permanent solution is implemented.

* Code of Federal Regulation, Title 10 - Energy, Part 50, Paragraph 50.55a. 


\section{NOTE FOR RECIPIENTS OF DRAFT NUREG 0313 REVISION 2}

There are several statements in Draft NUREG 0313 Rev. 2 that may be subjuct to misinterpretation. The following clarifications are provided, and should be kept in mind while reading the report.

Although the report points out that the staff preference is that piping with significant degradation should be replaced with IGSCC resistant material, this is intended only to reflect the technical preference of the staff, and is not intended to imply that such action will be required, or that it constitutes a staff position.

The report inciudes a staff recommendation that a stress improvement treatment should be used in conjunction with pipe replacement, and that hydrogen water chemistry should be implemented as soon as practicable. These statements should be interpreted only as representing the staff's technical judgemerit, and are not to be construed as requirements or formal staff positions.

The "Staff Positions" presented in the draft report should be construed as staff technical conclusions. The specific staff positions are stated in the proposed Generic Letter being issued concurrently for public comment. 
This package contains the following:

- NUREG-0313, Revision 2, "Draft Report for Comment, Technical Report on Material Selection and Processing Guidelines for BWR Coolant Pressure Boundary Piping."

- Enclosure 1 - Federal Register Notice

- Enclosure 2 - Draft Generic Letter for Public Comment

June 1986

Division of BWR Licensing

Office of Nuclear Reactor Regulation

U. S. Nuclear Regulatory Commission 
ENCLOSURE 1

FEDERAL REGISTER NOTICE 
Draft Revision to NUREG and An Implementing Generic Letter

The Nuclear Regulatory Commission has issued for public comment a draft of a proposed revision to NUREG-0313 "Technical Report on Material and Processing Guidelines for BWR Piping." Concurrently, a draft of the proposed implenenting Generic Letter is also being issued for public comment.

The Generic Letter includes the Staff Positions that will be used by the staff to evaluate the adequacy of actions taken by owners of BWR's to minimize and control intergranular stress corrosion cracking in BWR piping systems.

Further technical background and discussion is provided by the draft revision to NUREG-0313.

It has been suggested that consideration be given to limiting the fraction of weldments in a piping system that can contain cracks larger than those acceptable under ASME Boiler and Pressure Vessel Code Section XI, IWB-3500, with or without repairs such as weld overlay reinforcement. In IWB-3600, the Code provides evaluation methods for cracks larger than those acceptable under IWB-3500, but no limit is placed on the number of weldments in a system that may contain cracks acceptable by evaluation. A limit of about $25 \%$ of the weldments in any single system has been suggested. To ensure that this suggestion be given proper and full consideration, the following proposed addition to the draft Generic Letter is also being issued for public comment:

Limits on Number of Cracked Weldments in Piping

The maximum number of weldments with significant cracking that is permissible in a single piping system is $25 \%$ of the total number of welds in that system. Examples of piping systems are the Recirculation System, Core Spray System, RHR System and similar systems.

The maximum number of weldments with significant cracks that is permissible in a single run of piping is $25 \%$ of the total number of weldments in that run, or a total of two, if the run contains less than eight weldments.

Significant cracks are herein defined as those that cannot be shown to be acceptable under IWB-3500 irrespective of any weld overlay reinforcement or other similar repair that does not eliminate the crack.

A single pipe run is herein defined as a section of pipe between terminal ends, such as vessels, pumps, or valves.

Because crack sizing is difficult and uncertain in the crack depth range that is acceptable under IWB-3500, sizing to show conformance with IWB-3500 must be performed by two independent examiners, and both must be qualified for sizing under the NRC-EPRI-BWROG Coordination Plan being conducted at the EPRI NDE Center at Charlotte, North Carolina. 
Public comments are being solicited on both drafts, the Generic Letter and the draft revision to the NUREG. Comments should be accompanied by supporting data. Written comments may be submitted to the Rules and Procedures Branch, Division of Rules and Records, Office of Administration, U.S. Nuclear Regulatory Commission, Washington, DC 20555. Comments may also be delivered to Room 4000, Maryland National Bank Building, 7735 01d Georgetown Road, Bethesda, Maryland from 8:15 a.m. to 5:00 p.m. Copies of comments received may be examined at the NRC Public Document Room, 1717 H Street, N.W., Washington, DC 20555. For comments to be considered by the staff when finalizing these documents, they should be received no later than 60 days from the issuance of this notice.

The draft Generic Letter, the draft revision 2 to NUREG-0313, and the regulatory analysis pertaining to these are available for inspection at the Commission's Public Document Room, 1717 H Street N.W. , Washington, DC 20555. Requests for single copies of these documents (which may be reproduced) should be made in writing to the U.S. Nuclear Regulatory Commission, Washington, DC 20555, Attention: Director, Division of Technical Information and Document Control. Telephone requests cannot be accommodated. Generic Letters and NUREG Reports are not copyrighted, and Commission approval is not required to reproduce them.

(5 U.S.C. $552(a)$ )

Dated at Bethesda this //Lt/L day of

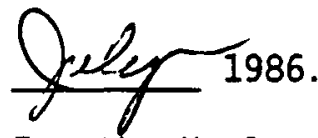

For the Nuclear Regulatory Commission

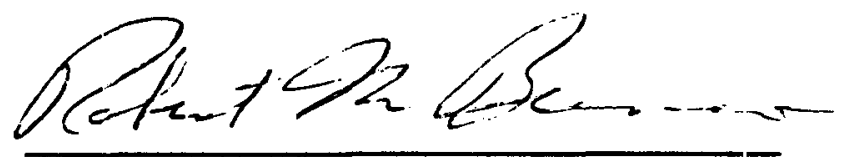

Robert M. Bernero, Director Division of BWR Licensing Office of Nuclear Reactor Regulation 
ENCLOSURE 2

DRAFT GENERIC LETTER 


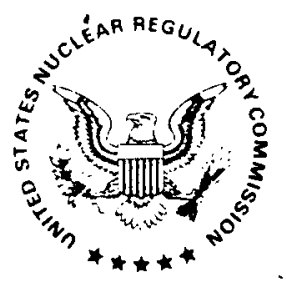

UNITED STATES

NUCLEAR REGULATORY COMMISSION

IVASHINGTON, D. C. 20555

(DRAFT)

TO ALL LICENSEE OF OPERATING REACTORS, APPLICANTS FOR OPERATING LICENSE, AND HOLDERS OF CONSTRUCTION PERMITS FOR BOILING WATER REACTORS (BWRS)

Gentlemen:

SUBJECT: $\quad$ NRC POSITION ON IGSCC IN BWR AUSTENITIC STAINLESS STEEL PIPING (Generic Letter 86- )

Intergranular stress corrosion cracking (IGSCC) near weldment.s in BWR piping has been occurring for almost 20 years. Early cases were in relatively small-diameter piping. In early 1982, cracking was identified in largediameter piping in BWR recirculation systems. Since then, extensive inspection programs have been conducted on BWR piping systems. Results of these inspections have varied widely between plants; some were found to be relatively free of cracking, whereas others were found to be severly degraided. The cause of the IGSCC is a combination of sensitization of the conventional austentic stainless steel by welding, high residual tensile stresses on the inside surface near the welds, and dissolved oxygen and other aggressive contaminants in the BWR primary coolant.

A significant number of domestic and foreign BWR owners have replaced or plan to replace piping systems that have experienced IGSCC with more resistant material. Other owners are implementing countermeasures such as Induction Heating Stress Improvement (IHSI) or Hydrogen Water Chemistry (HWC) to reduce the susceptability of the piping to IGSCC. In many cases, cracked weldments have been repaired by reinforcing them with weld overlay.

Substantial efforts in research and development have been sponsored by the BWR Owners Group for IGSCC. The results of this program along with other related work by vendors, consulting firms, and confirmatory research sponsored by the NRC, have permitted the development of revised Staff Positions regarding the IGSCC problems.

The purpose of this letter is to implement these position. The technical bases for these positions are detailed in NUREG-0313, Rev. 2 "Technical Report on Material Selection and Process Guidelines for BWR Coolant Pressure Boundar.y." This revision to NUREG-0313 was prepared as a major task in the staff long range plan to deal with BWR pipe cracking that was presented to the Commis:ion in SECY 84-301. This revision includes the relevant recommendations of the Piping Review Committee Task Group on Pipe Cracking issued as NUREG-1061 VD7. 1 "Report of USNRC Piping Review Committee, and consideration of public comments on that document. NUREG-0313, Rev. 2 describes the technical bases for the staff positions on materials, processes, and primary coolant chemistry to minimize and control IGSCC problems. Inspection schedules and inspection sample sizes are based on the susceptability of weldments to initiation and propagation of IGSCC. Inspection schedules are comparable to those specified in Section XI of the ASME Boiler and Pressure 
Vessel Code in cases where the piping material is IGSCC resistant. Varying amounts of augmented inspections are specified for piping with a greater susceptability to cracking, less certainty about the effectiveness of mitigation measures used, or in cases where repairs have been performed. When improved water chemistry control with hydrogen additions is implemented, less augmentation of inspection schedules is required.

A detailed discussion of the bases for the staff positions on these subjects is provided in NUREG-0313, Rev. 2. The staff positions implemented by this Generic Letter are given below:

\section{Staff Position on Materials}

The materials considered resistant to sensitization and IGSCC in BWR piping systems are:

(1) Low carbon wrought austenitic stainless steel. These include $304 \mathrm{~L}$, 304NG, 316L, 316NG, and 347NG. Carbon must be as specified in Table 1 in NUREG-0313, Rev. 2 by both heat and product analyses. These materials must be tested for resistance to sensitization in accordance with ASTM $\mathrm{A} 262 \mathrm{E}$ or equivalent specification.

(2) Weld metal of type $308 \mathrm{~L}$ grade with a minimum of $8 \%$ ferrite as deposited. This may be used as a cladding on the inside of the pipe (often referred to as corrosion-resistant cladding (CRC)), but this is not recommended generally, as the cladding may make volumetric inspections more difficult.

(3) Cast austenitic stainless steel with less than $0.035 \%$ carbon and a minimum of $8 \%$ ferrite.

(4) High toughness, low strength carbon steel grades, with specified minimum yield strength of 35,000 psi or lower.

(5) Other materials such as nickel base alloys, etc., will be considered for special cases. Inconel 82 is the only nickel base weld metal considered to be resistant.

\section{Staff Position on Processes}

The processes considered to be fully qualified for providing resistance to IGSCC in new or replacement BWR piping welds are:

(1) solution heat treatment (SHT)

(2) heat sink welding (HSW)

(3) induction heating stress improvement (IHSI)

Although last pass heat sink welding (LPHSW) is not considered to be fully qualifed, specific cases may be evaluated individually. Stress improvement processes other than IHSI (e.g., Mechanical Stress Improvement Process) may be approved by the staff when all relevant aspects are evaluated. Specific cases may be approved individually. 


\section{Staff Position on Water Chemistry}

The staff believes that HWC may prove to be an effective countermeasure for reducing IGSCC in BWR piping, but further experience, development, and engineering for field implementation are required. Furthermore, it appears likely that plant specific conditions may affect the degree of control of oxygen and conductivity that is possible. For these reasons, reductions in piping inspection frequency based on the use of HWC will be considered on an individual case basis, at least at the present time.

The staff also believes that the successful development and application of HWC is highly important and desirable to reduce the probability of IGSCC in components other than piping, particularly in structures and components inside the reactor vessel.

Staff Position on Weld Overlay Reinforcement

Weld overlay reinforcement made in accordance with staff recommendations described in this report are considered to be acceptable at least for short-term operation. Weld overlay may be considered for longer term operation provided:

(1) The overlays are in conformance with the criteria of IWB 3600 of Section $X I$ of the ASME Boiler and pressure vessel code, and

(2) they are inspected in accordance with the staff position on inspection methods and personnel, by UT examiners and procedures qualified to inspect overlayed welds.

Weld overlays not meeting (1) above may be reinforced to the extent necessary, if desired.

\section{Staff Position on Partial Replacement}

Repair of cracked weldments by partial replacement can be considered to be fully effective if appropriate materials and weld processes are used, and therefore are considered to be resistant to IGSCC.

\section{Staff Position on Stress Improvement (SI) of Cracked Weldments}

SI may be considered as a partial mitigation process when applied to weldments with short or shallow cracks. Details of allowable crack sizes in this regard are covered in the next selection. Note that SI is only considered effective if it is followed by a qualified UT examination, and if cracks are found they must be sized, both in depth and length, by procedures and personnel qualified to perform sizing examination. 
Staff Position on Clamping Devices

Clamping devices may be used for at least temporary reinforcement of cracked weldments. Each case must be reviewed and approved on an individual basis.

Staff Position on Crack Characterization and Repair Criteria

Methods and criteria for crack characterization and repair should be in conformance with IWB-3600 of Section XI of the ASME Boiler and Pressure Vessel Code.

Because detailed sections of the Code are still under development, methods of analysis and acceptance criteria described in detail in NUREG-0313, Rev. 2 are considered acceptable to the staff.

Staff Position on Inspection Methods and Personnel

Examinations should comply with the applicable Edition and Addenda of the ASME Code, Section XI, as specified in paragraph $(\mathrm{g})$, "Inservice Inspection Requirements" as 10 CFR 50.55a, Codes and Standards".

In addition, the detailed procedure, equipment and examination personnel shall be qualified by a formal program such as that being conducted in accordance with the NDE Coordination Plan agreed upon by NRC, EPRI, and the Boiling Water Reactor Owners Group for IGSCC, and being conducted at the EPRI NDE Center in Charlotte, North Carolina.

\section{Staff Position on Inspection Schedules}

A summary of the staff position on inspection schedules is given in Table 1 . Additional details and definitions are provided in NUREG-0313, Rev. 2, Section 5.

\section{Staff Position on Leak Detection}

Leakage detection systems should be in conformance with Position $C$ at Regulatory Guide 1.45 "Reactor Coolant Pressure Boundary Leakage Detection Systems.

Plant shutdown should be initiated for inspection and corrective action when any leakage detection system indicates, within a period of 24 hours or less, an increase in rate of unidentified leakage in excess of $2 \mathrm{gpm}$ or its equivalent, or when the total unidentified leakage attains a rate of $5 \mathrm{gpm}$ or its equivalent, whichever occurs first. For sump level monitoring systems with fixed-measurement interval method, the level should be monitored at 4-hour intervals or less. 
Unidentified leakage should include all leakage other than

(a) leakage into closed systems, such as pump seal or valve packing leaks that are captured, flow metered, and conducted to a sump or collecting tank, or

(b) leakage into the containment atmosphere from sources that are both specifically located and known either not to interfere with the operations of unidentified leakage monitoring systems or not to be from a throughwall crack in the piping within the reactor coolant pressure boundary.

Limits on Number of Cracked Weldments in Piping

The maximum number of weldments with significant cracking that is permissible in a single piping system is $25 \%$ of the total number of welds in that system. Examples of piping systems are the recirculation system, Core Spray System, RHR system and similär systems.

The maximum number of weldments with significant cracks that is permissible in a single run of piping is $25 \%$ of the total number of weldments in that run, or a total of two, if the run contains less than eight weldments.

Significant cracks are herein defined as those that cannot be shown to be acceptable under IWB-3500 irrespective of any weld overlay reinforcement or other similar repair that does not eliminate the crack.

A single pipe run is herein defined as a section of pipe between terminal ends, such as vessels, pumps, or valves.

Because crack sizing is difficult and uncertain in the crack depth range that is acceptable under IWB-3500, sizing to show conformance with IWB- 3500 must be performed by two independent examiners, and both must be qualified for sizing under the NRC-EPRI-BWROG Coordination Plan being conducted at the EPRI NDE Center at Charlotte, North Carolina.

The staff continues to believe that replacing susceptible piping with IGSCC-resistant materials will provide the greatest degree of assurance against future cracking problems. Therefore, we continue to endorse Generic Letter 84-07, "Procedural Guidance for Pipe Replacements at BWR's" and encourage programs to replace piping so as to reduce the potential for cracking and to minimize the need for augmented inspections. However, we recognize that if the staff positions of this Generic Letter are implemented, adequate levels of plant safety can be achieved. We believe this revision to the NUREG will be of use to owners in making sound plant-level decisions. 
Each weldment can be evaluated for its material, heat treatment history, stress level, chemical environment and surveillance program and, therefore, a reasonable judgement can be made on the long-term acceptability of that weldment. Considering that each piping system has many weldments and each plant has many piping systems, an owner needs to assess the entire problem in an integrated way.

BWR owners are requested to provide the staff the following:

1. Owner's current plans with regard to pipe replacement and/or other measures to be instituted to mitigate IGSCC and provide assurance of continued, long-term piping integrity and reliability.

2. A change to the facility(ies) Technical Specifications incorporating an augmented inspection program for austenitic stainless steel piping, 4 inches or greater, that operate at a temperature greater than $200^{\circ} \mathrm{F}$ in accordance with Table 1.

As in the past, should flaws be identified that are in excess of ASME Code Section XI criteria for continued operation without evaluation, evaluation of the flaws for continued operation and/or repair plans by the owner will be subject to NRC review and approval.

Licensees and applicants are requested to respond to this generic letter within 180 days of receipt of this letter. Our review of your submittal of information in response to this letter is not subject to fees under the provisions of 10 CFR 170 . However, should you, as part of your response or in a subsequent submittal, include an application for license amendment or other action requiring NRC approval, it is subject to the fee requirements of 10 CFR 170 with remittance of an application fee of $\$ 150$ per application (Sections 170.12(c) and 170.21) and subsequent semi-annual payments until the review is completed or the ceiling in Section 170.21 is reached.

This request for information was approved by the Office of Management and Budget under clearance number 3150-0011 which expires September 30, 1986. Comments on burden and duplication may be directed to the Office of Management and Budget, Reports Management Room 3208, New Executive Office Building, Washington, D.C. 20503.

Sincerely,

Robert M. Bernero, Director Division of BWR Licensing Office of Nuclear Reactor Regulation

Enclosure:

NUREG-0313, Rev. 2 
TABLE 1

INSPECTION SCHEDULES FOR BWR PIPING WELDMENTS

\begin{tabular}{llll} 
DESCRIPTION OF WELDMENTS & IGSCC & INSPECTION \\
Resistant Materials & CATEGORY & \multicolumn{1}{c}{ EXTENT \& SCHEDULE } \\
\hline & $A$ & AII Bimetallic every 10 yrs \\
& & All terminal ends every 10 yrs \\
& $25 \%$ of other welds every 10 yrs
\end{tabular}

\begin{tabular}{ll}
\hline Nonresistant Matls & (1) B \\
SI within 2 yrs of & B Bimetallic every 10 yrs \\
Operation (1) & All Terminal Ends every 10 yrs \\
& $50 \%$ others every 10 yrs
\end{tabular}

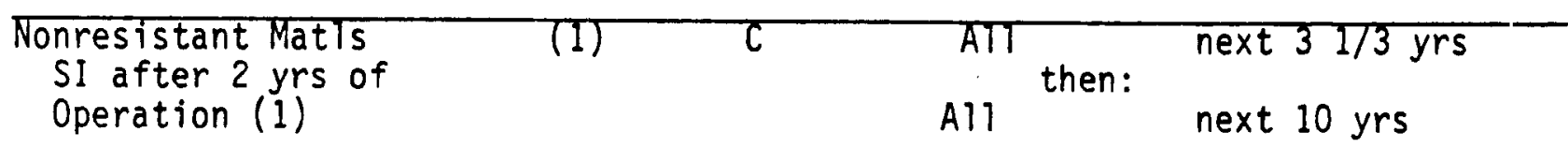

Non Resistant Mat? No SI

(1) D ATT Every $31 / 3$ yrs

\begin{tabular}{llll}
\hline $\begin{array}{l}\text { Cracked } \\
\text { overlayed or SI (1)(2) }\end{array}$ & $(1)(2)$ & E & All then: \\
& All & next outage \\
every $31 / 3$ yrs
\end{tabular}

\begin{tabular}{lllll}
\hline $\begin{array}{l}\text { Cracked } \\
\text { Inadequate or }\end{array}$ & $(2)$ & F & AाT & every outage \\
No Repair (2) & & & & \\
\hline $\begin{array}{l}\text { Non Resistant } \\
\text { Not Inspected (3) }\end{array}$ & $(3)$ & G & AाT & next outage
\end{tabular}

Not Inspected (3)

Notes:

(1) All welds in non-resistant material should be inspected after a stress improvment process as part of the process. Schedules shown should be followed after this initial inspection.

(2) See requirements for acceptable weld overlay reinforcements and stress improvement mitigation in Section 4 of NUREG-0313, Rev.2.

(3) Welds that are not inspectable should be replaced, "sleeved", or local leak detection applied. 
TABLE OF CONTENTS

Acronyms

Executive Summary

Page

vii

1.0 Introduction $\quad 1.1$

1.1 History 1.1

1.2 Revision 1 of NUREG-0313 1.2

1.3 Revision 2 of NUREG-0313 1.2

1.4 Bases for Recommendations 1.3

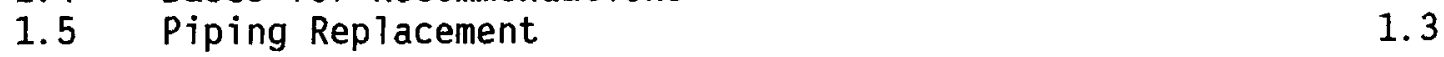

2.0 Methods to Reduce or Eliminate IGSCC $\quad 2.1$

2.1 Materials for New or Replacement Piping 2.1

2.1.1 Staff Position on Materials 2.2

2.2 Processes for New, Replacement, or Older Piping 2.3

2.2.1 Staff Position on Processes 2.4

2.3 Water Chemistry Modifications 2.5

2.3.1 Staff Position on Water Chemistry 2.6

3.0 Evaluation and Repair of Cracked Weldments 3.1

3.1 Repair Procedures 3.1

3.1.1 Weld Overlay Reinforcement 3.1

3.1.2 Partial Replacement 3.2

3.1.3 Stress Improvement 3.2

3.1.4 Mechanical Clamping Devices 3.3

3.2 Staff Position on Repairs 3.3

3.2.1 Staff Position on Weld Overlay Reinforcement 3.3

3.2.2 Staff Position on Partial Replacement 3.3

3.2.3 Staff Position on SI of Cracked Weldments 3.3

3.2.4 Staff Position on Clamping Devices 3.3

4.0 Crack Characterization and Repair Criteria 4.1

4.1 Flaw and Repair Evaluation Criteria 4.1

4.2 Crack Growth Calculations 4.1

4.3 Multiple and Complex Crack Characterization 4.2

4.4 Weld Overlay Design Criteria 4.3

4.4.1 Standard Overlay Design 4.3

4.4.2 Designed Overlays 4.3

4.4.3 Limited Service Overlays 4.4

4.5 SI Crack Mitigation Criteria 4.4

5.0 Inspection of Piping for IGSCC

5.1 Weldments Subject to Inspection 5.1

5.2 Inspection Methods 5.1

5.2.1 Staff Position on Inspection Methods and Personnel 5.1

5.2.2 Flaw Size Uncertainty 5.2

5.3 Inspection Frequency 5.2 
5.3.1 Weldment Condition Category Definitions 5.2

5.3.1.1 Definition of Category A Weldments 5.3

5.3.1.2 Definition of Category B Weldments 5.3

5.3.1.3 Definition of Category C Weldments 5.3

5.3.1.4 Definition of Category D Weldments 5.3

5.3.1.5 Definition of Category $E$ Weldments 5.4

5.3.1.6 Definition of Category F Weldments 5.4

5.3.1.7 Definition of Category G Weldments 5.4

5.3.2 Staff Position on Inspection Schedules 5.4

5.3.2.1 Inspection Schedule for Category A Weldments 5.4

5.3.2.2 Inspection Schedule for Category B Weldments 5.4

5.3.2.3 Inspection Schedule for Category C Weldments 5.5

5.3.2.4 Inspection Schedule for Category D Weldments 5.5

5.3.2.5 Inspection Schedule for Category $E$ Weldments 5.5

5.3.2.6 Inspection Schedule for Category F Weldments $\quad 5.5$

5.3.2.7 Inspection Schedule for Category G Weldments 5.5

5.3.3 Inspection Schedules with HWC 5.5

5.3.4 Sample Expansion Method 5.6

6.0 Leak Detection 6.1

Appendix A - Crack Growth Calculations $\quad$ A.1 
ANL

ASME

ASTM

BWR

BWROG

CFR

CRC

EPRI

GE

GMAW

GTAW

HAZ

HSW

HWC

IGSCC

IHSI

ISI

LPHSW

NDE

NRC

PNL

PPB

PT

RHR

SECY

SHT

SI

UT
Argonne National Laboratory

American Society of Mechanical Engineers

American Society of Testing Materials

Boiling Water Reactors

Boiling Water Reactor Owners Group

Code of Federal Regulation

Corrosion Resistant Cladding

Electric Power Research Institute

General Electric

Gas Metal Arc Welding

Gas Tungsten Arc Welding

Heat Affected Zone

Heat Sink Welding

Hydrogen Water Chemistry

Intergranular Stress Corrosion Cracking

Induction Heating Stress Improvement

Inservice Inspection

Last Past Heat Sink Welding Process

Nondestructive Examinations

Nuclear Regulatory Commission

Pacific Northwest Laboratory

Part per Billion

Penetrant Inspection

Residual Heat Removal

Office of the Secretary of the Commission Solution Heat Treatment

Stress Improvement

Ultrasonic Testing 


\section{EXECUTIVE SUMMARY}

This revision to NUREG-0313, Rev. 1 "Technical Report on Material Selection and Processing Guidelines for BWR Coolant Pressure Boundary Piping" consolidates the staff positions regarding actions that should be taken to ensure that the relevant portions of regulation will continue to be met by all operating BWR plants.

The staff long range plan regarding BWR pipe cracks was presented to the Commission in SECY 84-301. A major task in this plan was to revise NUREG-0313 to consolidate interim staff positions (SECY-83-267C) and recommendations of the Piping Review Committee Task Group on Pipe Cracking, issued as NUREG-1061, Vol. 1.

The subjects covered by this revision include recommendations regarding piping and weld material, special processing to minimize crack susceptibility, improvements in BWR primary coolant chemistry and control, inspection requirements, repair methods, and leak detection. These recommendations and conclusions are consistent with those made in NUREG-1061, Vol. 1, and are summarized as follows:

BWR piping weldments are susceptible to intergranular stress corrosion cracking (IGSCC). The three elements that, in combination, cause IGSCC are, a susceptible (sensitized) material, a significant tensile stress, and an aggressive environment.

The staff position is that improvements in all three of these elements should be pursued. Nevertheless, significant reduction in the probability of IGSCC can be accomplished even by improving one or two of these three elements. From a practical standpoint, this is more readily accomplished in the near term.

There is no practical way to reduce the sensitization of weldments already installed, so the only way to reduce the susceptibility of the material is to replace the piping with material that is resistant to sensitization by welding. Solution heat treatment of individual spool pieces in the pipe fabrication shop before field erection is practicable, and is recommended. Materials considered by the staff to be adequately resistant to sensitization by welding are the following:

(1) Low carbon wrought austenitic stainless steel. These include $304 \mathrm{~L}$, $304 N G, 316 \mathrm{~L}, 316 \mathrm{NG}$, and 347NG.

(2) Weld metal of type $308 \mathrm{~L}$ grade with a minimum of $8 \%$ ferrite as deposited. This may also be used as a cladding on the inside of the pipe.

(3) Cast austenitic stainless steel with less than $0.035 \%$ carbon and a minimum of $8 \%$ ferrite.

(4) High toughness, low strength carbon steel grades, with specified minimum yield strength of $35,000 \mathrm{psi}$ or lower. 
(5) Other materials such as nickel base alloys, etc. will be considered for special cases. Inconel 82 is the only nickel base weld metal considered to be resistant.

Service-induced stresses on most BWR piping are relatively low. The source of the high stress primarily responsible for IGSCC is the high tensile stress on the inside of the pipe caused by normal welding practice. Stress Improvement (SI) can be accomplished on weldments already installed by the Induction Heating Stress Improvement (IHSI) process. Other SI methods are being evaluated by the staff.

SI can be applied to new or replaced piping, or can be applied at any time during plant life. The staff strongly recommends that SI be applied on all new or replacement piping, and preferably within two years for piping already installed. For piping with more than 2 years of operation, SI is considered to be less effective, because cracking may already be present.

BWR primary coolant normally contains oxygen from radiolytic dissociation of water, and also contains other impurities such as chlorides, carbonates, and sulfur species. If the oxygen levels are reduced by using hydrogen injection, and other impurities are kept to very low levels, IGSCC of even sensitized material will be drastically reduced. This combination of water chemistry improvement is referred to as Hydrogen Water Chemistry (HWC). The staff recommends that HWC be implemented as soon as the practical and safety aspects have been worked out.

Some utilities have decided not to replace piping at this time. The staff has developed guidelines for interim actions that should be taken in these instances. Augmented inspection schedules for susceptible and repaired weldments are based on judgment regarding the probability that significant cracks or leaks will develop, considering the effectiveness of any repair or mitigative actions applied.

In summary, the staff prefers that piping with significant cracking be replaced with more resistant material. Nevertheless, because even the more resistant materials are not completely immune from cracking if mistreated, or if the stress and environment are very severe, the staff also recommends that a SI process should be used in conjunction with replacement, and then HWC be implemented as soon as practicable. 


\section{TECHNICAL REPORT ON MATERIAL SELECTION AND PROCESSING GUIDELINES FOR BWR COOLANT PRESSURE BOUNDARY PIPING}

\subsection{INTRODUCTION}

\subsection{History}

The subject of intergranular stress corrosion cracking (IGSCC) at welds in boiling water reactor (BWR) piping has been of continuous concern for almost 20 years. An ever-increasing amount of research and developmental activity related to understanding the causes of the cracking and ways to prevent it has been going on during this time period. Under the auspices of NRC, two Pipe Crack Study Groups have reviewed the problem in BWRs--one in 1975 and the other in 1979. Reports of the findings of these groups were published (NUREG-75/067 and NUREG-0531), and staff guidelines prepared to implement their recommendations were published as NUREG-0313 entitled "Technical Report on Material Selection and Processing Guidelines for BWR Coolant Pressure Boundary Piping," and NUREG-0313, Revision 1.

Until recently, significant cracking of large-diameter piping (12-in. diameter and larger) was considered to be relatively unlikely, and even if it occurred it was expected that cracks would remain shallow. In Japan some cracks had been detected in the 12-in-diameter recirculation riser pipes. Because of this, NUREG-0313, Rev. 1 recommended that augmented inservice inspection (ISI) on a sampling basis be performed for these pipe:s. Shallow cracking was discovered in pipes larger than 12-in-diameter in Germany, but it was not clear that either the Japanese or German experience was relevant to plants built in the United States.

During a hydrostatic test in March 1982, slight leakage was detected at two of the furnace-sensitized recirculation safe ends at Nine Mile Point. When these safe ends had been examined ultrasonically 9 months earlier, no cracking was reported. Additional ultrasonic testing (UT) using more sensitive procedures disclosed cracks at many of the 28 -in-diameter recirculation piping welds.

This finding was important for two reasons:

(1) It could no longer be believed that large pipes were relatively immune to significant cracking.

(2) It cast doubt on the adequacy of the UT procedures used at that time to detect cracks in large pipes.

IE Bulletin 82-03 was issued to specify augmented inspections of large piping in the recirculation systems of plants ( 9 units) with outages scheduled in late 1982 and spring 1983. It also specified that 
inspection teams demonstrate that they could detect and properly identify cracks in large-diameter pipe welds. IE Bulletin 83-02 was later issued to require inspections at al1 other operating BWRs (14 units) with more than 2 years of operating service, and to upgrade the UT performance capability demonstrations required of the inspection teams. Reinspections at the next refueling outage were required by Generic Letter 84-11, which also provided specific guidance regarding flaw evaluation and repair for interim operation.

The results of these inspections varied greatly from plant to plant. Some found very little, if any, cracking. Others found very significant cracking in a large percentage of the recirculation, residual heat removal (RHR) system, and reactor water cleanup system piping welds.

The discovery of significant cracking in the large-diameter piping, the development of ASME Code procedures for evaluating flaws in such piping, and results of further development of materials and processes to mitigate or prevent IGSCC led to the decision to revise NUREG-0313.

\subsection{Revision 1 of NUREG-0313}

NUREG-0313 was revised in 1980 to provide guidance and recommendations regarding materials and processes that could be used to minimize IGSCC and to provide recommendations about augmentation of the extent and frequency of ISI on welds considered to be susceptible to IGSCC.

Revision 1 also provided recommendations about upgrading leak detection systems and leakage limits for plants with susceptible welds.

\subsection{Revision 2 of NUREG-0313}

This present (second) revision updates these recommendations and adds several subjects:

(1) It provides guidance for performing ASME Code, Section XI, IWB 3600 , calculations for flaw evaluation.

(2) It provides recommendations regarding repair of cracked piping.

(3) It recommends formal performance demonstration tests for UT examiners, such as those prescribed by IE Bulletins 82-03 and 83-02, and currently being conducted under the NDE Coordination Plan, agreed upon by NRC, EPRI, and the BWROG. This will provide additional assurance that inspections for IGSCC in BWR piping will be performed in an effective manner.

The approach used in previous editions of NUREG-0313 to identify welds that require augmented inspection is simplified, but is expanded to include consideration of reinspections of welds found to be cracked, with or without repair or mitigation actions. The current approach is based on the following: 
(1) A11 stainless steel welds in high-temperature BWR systems are considered to be subject to IGSCC unless measures have been taken to make them resistant.

(2) The frequency and sample size used to inspect all safety related piping welds in BWR plants will depend on the material and processing used. Simple bases are provided for such classification.

(3) Some utilities may choose not to replace, or to operate for some interim period of time before making major modifications or replacing piping. This would mean that operation with cracked or repaired welds will be desired. Guidance is provided to cover these situations.

\subsection{Bases for Recommendations}

Extensive work sponsored by industry through the Electric Power Research Institute (EPRI), General Electric (GE), and the U.S. Nuclear Regulatory Commission (NRC) has been carried out since the second Pipe Crack Study Group reported in 1978-1979 (NUREG-0531). It is not the objective of this report to cover this work in detail. NUREG-1061, Vol. 1 was prepared by the Pipe Crack Task Group of the Piping Review Committee. It represents an in-depth discussion of the technical aspects of IGSCC in BWR piping, and provides recommendations regarding materials and processes available to mitigate or eliminate the problem. It also includes a discussion of the technical basis for the guidelines for interim operation used by the staff.

This revision is based primarily on the information presented in NUREG-1061, as modified by more recent advances in ultrasonic testing, and fracture mechanics evaluation methods. It also takes cognizance of work in progress related to serviceability of cracked pipes reinforced by weld overlay or mitigated by IHSI being performed at General Electric and PNL under EPRI and the BWROG sponsorship, and related work at ANL funded by the NRC, as well as public comments received on NUREG-1061, Vol. 1.

\subsection{Piping Replacement}

As stated in the staff paper to the Commission (SECY-84-301), it is the staff's long range goal to bring all affected plants back to meet regulations without undue reliance on augmented inspections. Therefore, it is desired that utilities with degraded piping systems replace such piping with IGSCC resistant material as soon as practicable. Serious consideration should also be given to weld joint design, welding processes, and SI processes to provide residual stress improvement to the new piping.

Procedural guidance regarding pipe replacement licensing activities is provided in Generic Letter 84-07, dated March 14, 1984. 


\subsection{METHODS TO REDUCE OR ELIMINATE IGSCC}

There are three primary ways to minimize the occurrence of IGSCC in BWR piping:

(1) Use material that is not subject to sensitization by welding.

(2) Use processes that reduce the tensile stress level at the inner surface of the pipe near the weld.

(3) Modify the BWR water chemistry to control the levels of oxygen and other aggressive contaminants to very low levels.

Each of these three basic approaches are discussed below, and regulatory positions regarding each are presented.

\subsection{Materials for New or Replacement Piping}

Sensitization involves carbon in solution forming carbide at grain boundaries upon moderate heating; therefore, reducing the carbon content of the material will result in reducing the degree of sensitization resulting from a given thermal exposure, assuming that other factors remain equal. However, because the susceptibility of an austenitic stainless steel is also affected by other variables, such as grain size, previous heat treatment, amount of cold work, trace impurities, and overall compositional balance, complete dependence on reduced carbon content may not be effective unless the carbon level is very low. Nevertheless, a high degree of protection against IGSCC will result if the carbon content is kept below $0.035 \%$, as specified for type $304 \mathrm{~L}$ grade material. Freedom from sensitization will be much more certain if the carbon levels are controlled to even lower levels.

If carbon is limited to very low levels (such as below $0.02 \%$ ), the strengthening effect of the carbon is lost, and the material has lower strength, which results in lower Code-allowable stresses. Some heats of type 304L material will also have strength levels too low to meet the minimum specified strength level for standard type 304 . Therefore, the replacement of piping with low carbon grades may require redesigning or using thicker wall pipes.

Industry has overcome these problems by developing special grades of austenitic stainless steel. Carbon content is kept very low, and the reduction in strength is compensated for by adding controlled amounts of nitrogen. Molybdenum is often added; it enhances strength and resistance to sensitization. 
Table 1 shows the grades of Series 300 stainless steels that were developed for increased resistance to sensitization in piping.

Table 1 Series 300 stainless steels developed for increased resistance to sensitization

\begin{tabular}{lllllc}
\hline Stee & $\begin{array}{l}\text { C\%, } \\
\max \end{array}$ & $\mathrm{Cr} \%$ & $\mathrm{Ni} \%$ & Mo $\%$ & $\mathrm{~N} \%$ \\
\hline 304L & 0.035 & $18.0-20.0$ & $8-10.5$ & -- & -- \\
304NG* & 0.02 & $18.0-20.0$ & $8-12.0$ & -- & $0.06-0.10$ \\
316L & 0.035 & $16.0-18.0$ & $10.0-14.0$ & $2.0-3.0$ & -- \\
316NG* & 0.02 & $16.0-18.0$ & $10.0-14.0$ & $2.0-3.0$ & $0.06-0.10$ \\
347NG & 0.03 & $17.0-19.0$ & $9.0-13.0$ & $* *$ & \\
\hline
\end{tabular}

*304NG and $316 N G$ were formerly called $304 \mathrm{~K}$ and $316 \mathrm{~K}$, respectively. $* *$ Minimum $\mathrm{Nb}+\mathrm{Ta}=10 \times \% \mathrm{C}$.

Weld metal with low carbon and controlled ferrite (such as $308 \mathrm{~L}$ with $8 \%$ minimum ferrite) is resistant to sensitization and IGSCC. This resistance is also somewhat dependent on the microstructure produced by the specific welding process used. Weld passes diluted with high carbon base material will not have suitable resistance.

Cast austenitic stainless steel with low carbon and high ferrite content is also resistant to sensitization and IGSCC.

Other common materials such as low strength, high toughness, carbon steels are suitable for many BWR piping systems and are immune to the problem of sensitization and resultant IGSCC. Higher strength alloy steels are less desirable; they may be subject to other types of cracking.

\subsubsection{Staff Position on Materials}

The materials considered resistant to sensitization and IGSCC in BWR piping systems are:

(1) Low carbon wrought austenitic stainless steel. These include $304 \mathrm{~L}$, $304 N G, 316 \mathrm{~L}, 316 \mathrm{NG}$, and 347NG. Carbon must be as specified in Table 1 by both heat and product analyses. These materials must be tested for resistance to sensitization in accordance with ASTM A262E or equivalent specification.

(2) Weld metal of type $308 \mathrm{~L}$ grade with a minimum of $8 \%$ ferrite as deposited. This may be used as a cladding on the inside of the pipe (often referred to as corrosion-resistant cladding (CRC)), but this is not recommended generally, as the cladding may make volumetric inspections more difficult. 
यका

(3) Cast austentic stajiess steel with iess than $0,035 \%$ carbon and a minimum of $8 \%$ ferrite

(4) High toughness, 10 ow strength carbon steel grades, with specified minimum yjeld strength of 35,000 psior ower.

(5) other materials such as nickej base aloys etc wi be considered for special cases. Incone 72 is the only nickel base weld metal considered to be resistant.

\subsection{Processes for New, Replacement, or 0lder Piping}

Special or controlled processing during or after fabrication can provide protection, from, IGSCC in three ways:

(1) removing sensitization,

(2) preventing sensitization, and

(3) providing favorable state of residual stress.

There are several special processes that have provedeffective in one or more, of these ways they are discussed below:

Solution Heat Treatment

The normal metallurgical treatment used to ensure freedom from sensitization is to perform a complete solution heat treatment (SHT) to the piece after welding or other processing. It consists of heating the material to a high enough temperature to dissolve all carbides, then cooling fast enough to retain the carbon in solution standard specifi. cations are used to control the process the chief concernis providing

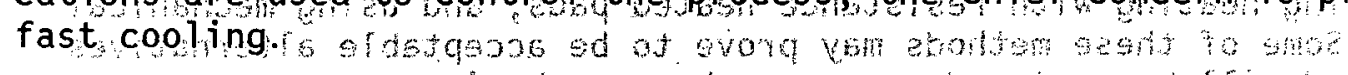

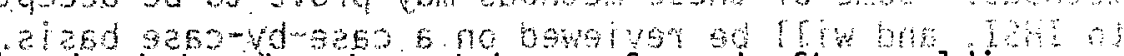

Note that the solution heat treatment must be performed after welding, and complex piping sections may be difficult to cool fast enough from the solution temperature. Interiors of long or complex piping runs may

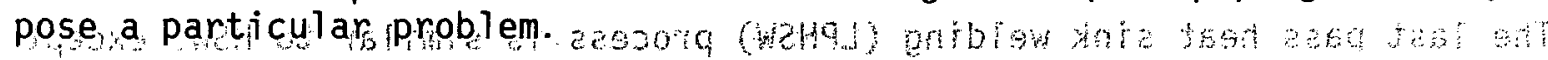
To be effective solution heat treatments must pe performed in accordance with written procedures that have been proven to be effective for the size and geometry of the piece, and must be in accordance with applicable specifications.

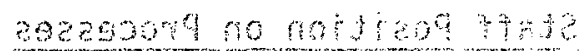

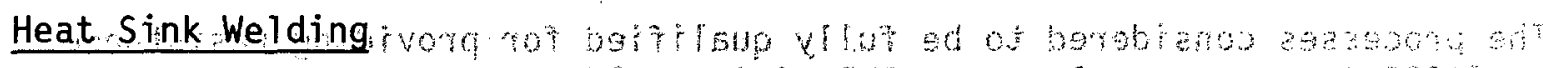
Heat sink welding (HSW) is a term applied to a method of butt welding pipes or fittings in which the major portion of the weld is produced with cooling water inside the pipe. The cooling effect of the water 
minimizes the sensitization caused by the welding process, and in addition, produces a steep temperature gradient through the pipe wall during welding. This steep temperature gradient causes tensile thermal stresses on the inside of the pipe to exceed the yield strength of the material. After the welding is completed and the weldment is cooled, the inner portion of the weld is under high compressive residual stress. This is the opposite of what is caused by normal welding. The high compressive stresses are maintained through about half the wall thickness. The combination of reduced sensitization and high beneficial residual stresses provides significant resistance to IGSCC.

Induction Heating Stress Improvement

Induction heating stress improvement (IHSI) is a process originally developed in Japan for treating piping weldments already fabricated or installed in a plant. It consists of heating the outside of the pipe by induction coils to controlled temperatures $\left(\sim 800^{\circ} \mathrm{F}\right)$ while cooling water is circulated inside the pipe. The high thermal gradients produce the same effect as HSW. The inside of the pipe is stretched during the process, causing high residual compressive stresses after the process is completed. This process is fully effective for uncracked weldments even if they have significant service, unless service stresses are extremely high. In this case, the beneficial compressive stresses may be defeated. For IHSI to be considered fully effective, the total service stress, including thermal stress but excluding seismic stress, should be less than $1.5 \mathrm{~S}_{\mathrm{p}}$, where $\mathrm{S}_{\mathrm{m}}$ is the Code specified allowable primary membrane stress intensity at design temperature.

\section{Other Stress Improvement Processes}

There are ways that may effect the desired change in the residual stress pattern caused by welding other than using induction heating. These include using heating with resistance heated pads, and using mechanical methods. Some of these methods may prove to be acceptable alternatives to IHSI, and will be reviewed on a case-by-case basis.

Last Pass Heat Sink Welding

The last pass heat sink welding (LPHSW) process is similar to HSW, except that only the last welding passes are performed when there is cooling water inside the pipe. Although some preliminary tests appear promising, it cannot be considered to be fully effective at this time.

\subsubsection{Staff Position on Processes}

The processes considered to be fully qualified for providing resistance to IGSCC in new or replacement BWR piping welds are:

(1) solution heat treatment (SHT)

(2) heat sink welding (HSW)

(3) induction heating stress improvement (IHSI) 
Although last pass heat sink welding (LPHSW) is not considered to be fully qualified, specific cases may be evaluated individually. Stress improvement processes other than IHSI (e.g., Mechanical Stress Improvement Process) may be approved by the staff when all relevant aspects are evaluated. Specific cases may be evaluated individually.

\subsection{Water Chemistry Modifications}

Intergranular stress corrosion cracking of sensitized and stressed stainless steel requires a corrosive environment. Although BWR reactor coolant is comparatively pure water, the small amounts of impurities usually present are enough to cause IGSCC. These impurities fall into two general classes; those that increase the oxidizing potential, and those that increase the electrical conductivity of the water. Both must be reduced to very low levels in order to achieve an electrochemical potential below which IGSCC cannot be initiated.

0xygen is formed in the core of light water reactors by the disassociation of water by radiolysis. This reaction can be inhibited by the addition of hydrogen to the water, as is done in pressurized water reactors. Until recently, this was not considered to be feasible in boiling water reactors, therefore, the normal oxygen content of BWR reactor water is about 200 parts per billion ( $P$ PB), providing an oxidizing environment conducive to IGSCC in the entire BWR primary system.

Efforts to find ways to reduce the oxygen levels in BWRs led to the develcpment of a hydrogen addition methodology that appears to be effective and practicable. Tests conducted in the Dresden 2 plant over the past severa] years indicate that oxygen levels can be reduced to levels of 10 to 20 PPB, although occasional excursions to higher levels may occur. Tests indicate that IGSCC will not occur at an oxygen level of 20 PPB or less, if other contaminants are controlled to keep conductivity low.

Contaminants that increase the conductivity of the reactor water can come from several sources, such as condenser leakage, resin beds, etc. They include chlorides, carbonates, and sulfur species. Because the electrochemical potential causing IGSCC depends on both the oxidizing state and the conductivity of the water, the conductivity must be held to very low levels. Laboratory tests have indicated that conductivity levels should be kept to a maximum of 0.3 micro-Siemens ( $\mu S$ ) per centimeter with oxygen at 20 PPB or less to prevent IGSCC. Although the tests in Dresden 2 indicated that such conductivity levels could be attained, occasional excursions must be anticipated, and plant to plant variations are likely to be significant in this regard.

This combination of oxygen and conductivity control is commonly referred to as Hydrogen Water Chemistry, or HWC. Although tests have shown that HWC can inhibit IGSCC, many questions regarding radiation effects, fuel 


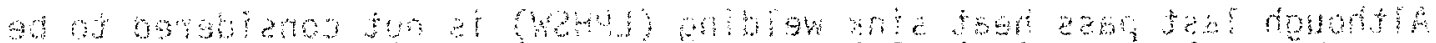
performance, etc are stjll bejng resolved. sojeld implementation and engineering are being actively pursued by the industry and it is expected that within the next few years, HWG wi 1 be considered a pract jal method of control.

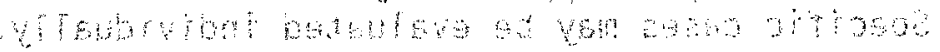

One very important aspect of HWC is that it willinhibity IGSCC in the entire primary system of BWRs. IGSCC in BWRs has not been conf ined to piping; there have been many cases of cracking in reactor vessel internal components such as controj rod drive housing penetrations, core spray as spargers, etco Although none of these cases have been considered to be safety problems reducing these occurrences would provide significant economic benef its; and therefore would be extremely desirable The staff therefore bel jeves that HWC should be adopted (when fully developed) even if other effective countermeasures for piping have been jomplemented.

\subsubsection{Staff Position on Water Chemistry}

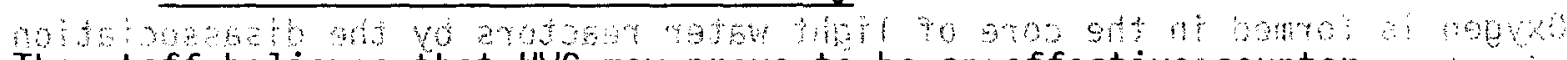
The staff believes that HWC may prove to be an effective counter measure for reducing IGSCC in BWR piping, but further experjence development and engineering for f i jo implementatjon are required Furthermore it appears likely that plant specifje conditions may affect the degree of control of oxygen and conductivity that is possibie. For these reasons, reductions in piping inspections frequency based on the use of HWC will be considered on an individual case basjs, at least at the present time.

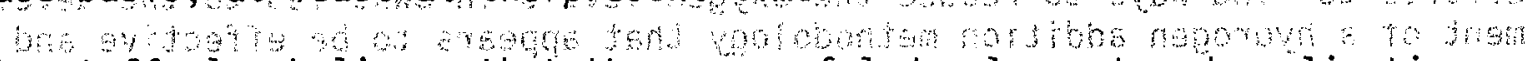
The staff al so believes that the successful development and application of HWC is highly important and desirabje to reduce the probabjity of IGSCC in components other than piping, particularly in structures and

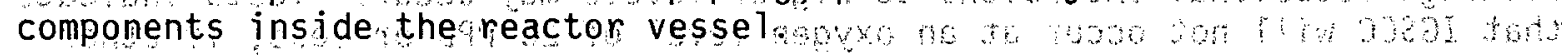

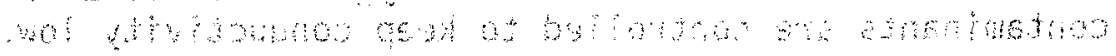

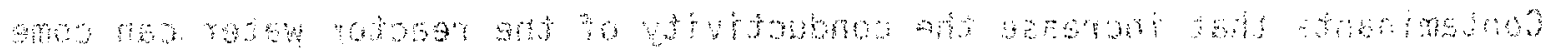

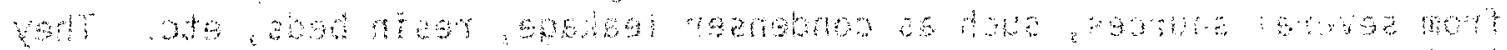

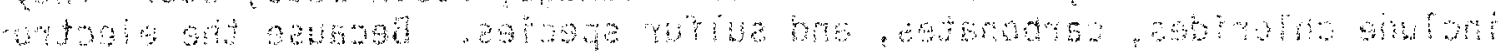

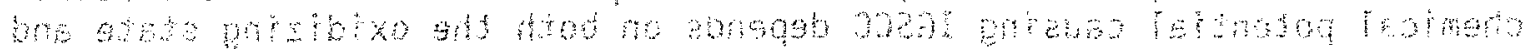

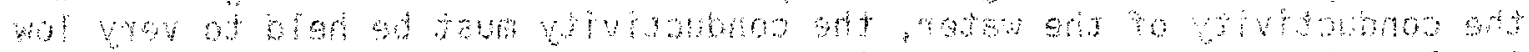

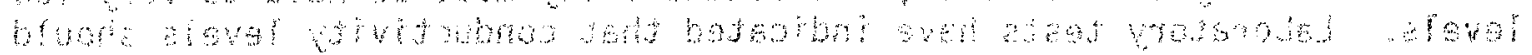

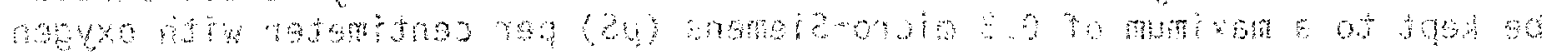

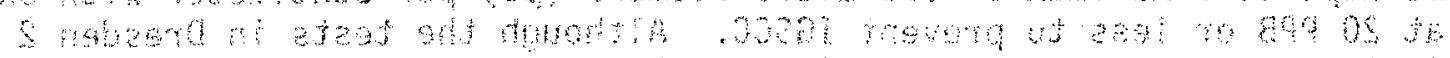

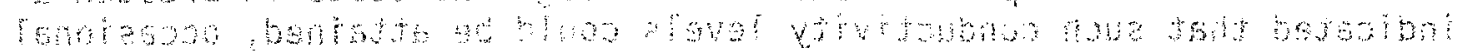

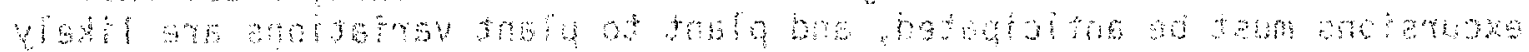

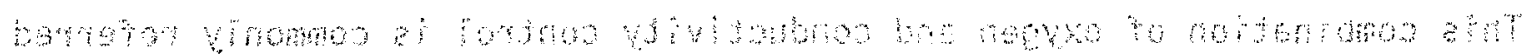

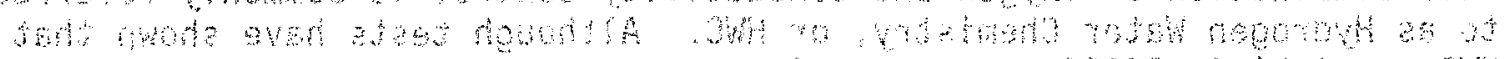

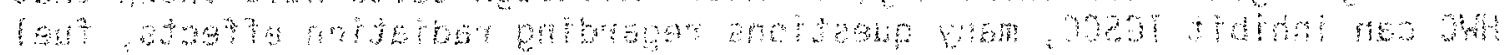




\subsection{EVALUATION AND REPAIR OF CRACKED WELDMENTS}

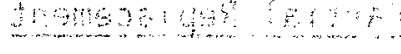

Whencracks are found in BWR tping, several alt ternatives (and

combinations) are availabiesto provide assurance of further safe opera-

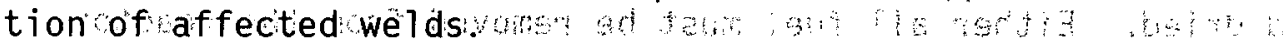

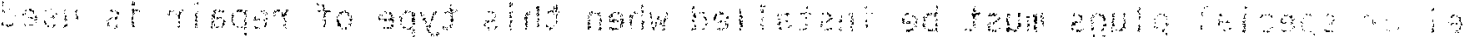

If the cracking is relativelyminor, the rules of ASME Code Section XI, IWB 3600 (as modified and expanded in Section 8) may be used for shortterm interimoperation further SI may be applied to reduce the probability of further crackigrowth.

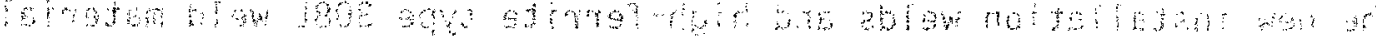

If the cracking is too severe to meet these rules, the affected piping must be repaired or replaced before the plant can be returned to service.

\subsection{Repair Procedures}

IGSCC in BWR piping initiates at the inner surface of the pipe and grows progressively through the wall toward the outside. It commonly initiates near the weld root and progresses up the heat-affected zone (HAZ) close to the weld, and sometimes in the weld: Therefore; cracking can affect a region of the pipe longer in axial extent than the maximum width of the weld if cracks occur on both sides of the weld. The usual repair process during construction is to grind out the defective area and fill the area with weld metal: This is not practical for repair of IGSCC, because IGSCC starts from the inside surface; requiring removal of essentially the entire weld: and $\mathrm{HAZ}$ area.

There are several repair methods available for at least short-term operation:

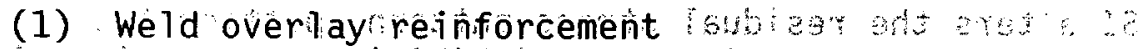

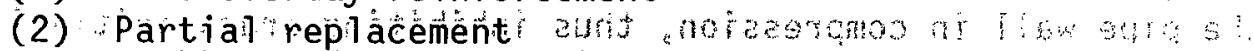

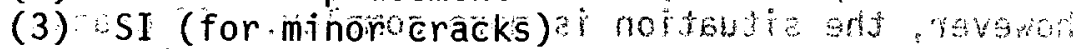

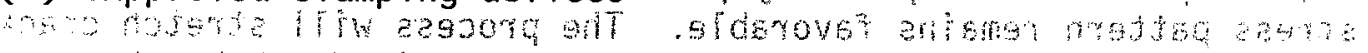

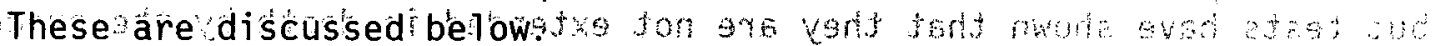

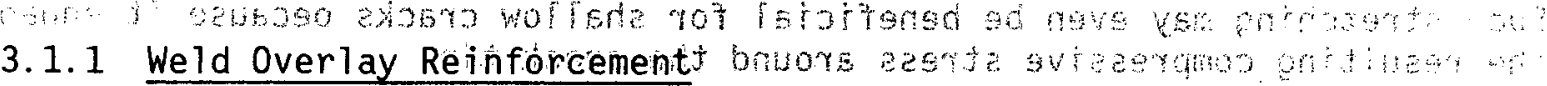

Weld over lay reliniforcement consists of appiying weld metalcover the we ld and for a specifiedsmingm distance beyond the weld on both sidesthis is done completely around the outside surface of the pipe over lapping each

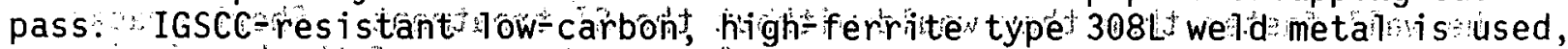
and the process is usually performe with an automatic welding machine using the Gas Tungsten arc (GTAW) or Gas Metal arc (GMAW) processes". "Weld overlay is performed with cooling water flowing through the pipe during welding, and there is no need to drain the pipe during repair. More specific design details and quality control requirements are covered in Section 4.0 . 


\subsubsection{Partial Replacement}

A very effective repair method is simply to cut out a section of the pipe containing the defective weldments and to weld in another piece of pipe. The major drawback to this approach is that the affected run of pipe must be drained and dried. Either all fuel must be removed from the reactor vessel or special plugs must be installed when this type of repair is used in portions of piping that cannot be isolated.

If this method can be used, a fully effective repair can be made with resistant material, using welding processes such as heat sink welding for the new installation welds and high-ferrite type $308 \mathrm{~L}$ weld material. SI can also be applied.

The major drawback to the use of this process (assuming that draining is feasible) is that high radiation exposures to workers may be encountered at older plants from the inner surfaces of the pipes. Prior decontamination can alleviate this problem.

Both weld overlay and partial replacement cause the pipe to shrink in the axial direction. If several such repairs are made in one length of pipe, additional stresses will be introduced by this shrinkage, which must be taken into account in the stress analysis required for the repair, and in the fracture mechanics analyses of crack growth in other welds of the pipe system. Measurements of shrinkage on weld procedure qualification test pieces can provide guidance regarding how much shrinkage can be expected. Actual measurements made during the repair should be used in the final stress analysis.

\subsubsection{Stress Improvement}

As discussed above, SI alters the residual stress pattern, putting the inner part of the pipe wall in compression, thus inhibiting crack initiation. If cracks are present, however, the situation is more complex. If cracks are shallow, the process will probably prevent further growth, as long as the residual stress pattern remains favorable. The process will stretch cracks open, but tests have shown that they are not extended in depth by the process. such stretching may even be beneficial for shallow cracks because it enhances the resulting compressive stress around the crack tip.

The tips of deeper cracks, particularly those penetrating deeper than half way through the pipe wall, are likely to be in a general tensile stress field after SI processes. This could cause such cracks to propagate through the wall faster than they would without the SI treatment. Short cracks however, will not be expected to grow longer, because of the beneficial residual stress on the inside portion of the pipe.

Therefore, both short cracks of medium depth, and longer shallow cracks are not expected to grow to a significant size. 


\subsubsection{Mechanical Clamping Devices}

Another approach to reinforcing a cracked weldment is to use a mechanical clamp. One advantage of this approach is that the clamp may be periodically removed for weld examination. Such clamping devices will be reviewed for adequacy of mechanical design, materials of construction, and installation methods on a case basis.

\subsection{Staff Position on Repairs}

\subsubsection{Staff Position on Weld Overlay Reinforcement}

Weld overlay reinforcement made in accordance with recommendations described in this report are considered to be acceptable at least for short-term operation. Weld overlay may be considered for longer term operation provided:

(1) The overlays are in conformance with the criteria of Section 4.0 of this report; and

(2) they are inspected in accordance with the criteria of Section 5.0 by UT examiners and procedures qualified to inspect overlayed welds.

Weld overlays not meeting (1) above may be reinforced to the extent necessary, if desired.

\subsubsection{Staff Position on Partial Replacement}

Repair of cracked weldments by partial replacement can be considered to be fully effective if appropriate materials and weld processes are used, and therefore are considered to be resistant to IGSCC.

\subsubsection{Staff Position on SI of Cracked Weldments}

SI may be considered as a partial mitigation process when applied to weldments with short or shallow cracks. Details of allowable crack sizes in this regard are covered in the next section. Note that SI is only considered effective if it is followed by a qualified UT examination, and if cracks are found they must be sized, both in depth and length, by procedures and personnel qualified to perform sizing examinations according to Section 5.1 of this report.

\subsubsection{Staff Position on Clamping Devices}

Clamping devices may be used for at least temporary reinforcement of cracked weldments. Each case must be reviewed and approved on an individual basis. 


\subsection{CRACK CHARACTERIZATION AND REPAIR CRITERIA}

\subsection{Flaw and Repair Evaluation Criteria}

This section provides guidance and staff positions regarding methods to evaluate IGSCC cracks for. limited further operation. It also covers evaluation methods and acceptance criteria for repairs if immediate pipe replacement is not practicable.

The methods and criteria described in this section are generally in accordance with IWB 3640 of Section XI of the ASME Boiler and Pressure Vessel Code. In particular, IWB 3642 provides for flaw evaluation using fracture mechanics or other applicable methods. The Code requires that crack growth be calculated, and the flawed joint is acceptable for further operation only for the time period that the flaw remains small enough that the Code-intended safety or design margins are maintained.

In IWB 3641, the Code (Winter 83 Addenda) provides simple tables of allowable crack depth as a function of the primary stress level and crack length. These tables are based on limit load calculations, and assume that the material is tough. An overall margin of about 2.77 against net section collapse (limit load) failure mode is provided.

It was recognized that they did not provide an acceptable level of margin against failure for low toughness materials such as fluxed welds (SAW, SMAW). This is because low toughness material may fail at load levels below limit load, and secondary stresses (not considered in the original IWB 3641 tables) may also contribute to failure of low toughness materials.

This problem has been addressed by the Code, and the 1985 Winter Addenda provides appropriate criteria for all types of welds.

The staff has also addressed this problem of lower toughness weld material, and has concluded that adequate margins against failure of the less tough flux welds can be provided by using a limit load analys is that includes an explicit margin of a factor of three on all stresses, including secondary stresses. Another simple alternative that will also provide comparable margins is to limit allowable crack depths to two-thirds of the values in the Winter, 1983 Addenda IWB 3641 tables, including secondary stresses in the code "stress ratio." In each of these methods, the maximum crack dept:h should be limited to $60 \%$ of the wall thickness, regardless of crack length.

\subsection{Crack Growth Calculations}

The rate of growth of cracks by IGSCC has been the subject of discussion and controversy for many years. Part of the problem is that the rate of growth is markedly affected by the degree of sensitization of the material and the severity of the environment. A further complication has been that ways to 
measure the degree of sensitization have proved to be inaccurate or not relevant to the particular problem of BWR piping. For these reasons, many crack growth tests have been performed that were either too severe or not severe enough. The staff has selected a crack growth rate curve that it believes to be near the upper bound for weld-sensitized material in actual BWR environments.

Crack growth by IGSCC follows what is now considered to be a classical trend. If the logarithm of the growth rate is plotted against the logarithm of severity of loading, measured by the stress intensity factor (a fracture mechanics parameter) $K_{I}$, a linear relationship is found. As the $K_{I}$ changes with crack growth, iterative calculations will track the growth of the crack with time. The calculational procedures used by the staff to predict crack growth are detailed in Appendix A.

Actual circumferential cracks in welds are usually very long in relation to the ir depth; therefore, crack growth in a congruent manner (maintaining the same shape) cannot be assumed, particularly for large-diameter pipes. The growth in the length direction, therefore, will be assumed to be much more than in the depth direction. Specifically, the growth along the length shall be assumed to increase the aspect ratio (length to depth) by the same factor that the depth is increased. For example, if a crack with an aspect ratio of 3 to 1 grows to twice the original depth, the new length will be assumed to give an aspect ratio of 6 to 1 . Cracks with aspect ratios over 20 to 1 are assumed not to change shape with crack growth.

Although axially oriented cracks are not likely to grow significantly beyond the sensitized zones on each side of the weld, they will grow through the weld if the weld is marginal in resistance to sensitization. Axial cracks will therefore be assumed to grow through the wall to a length equal to 1.5 times the thickness of the pipe.

\subsection{Multiple and Complex Crack Characterization}

\section{Case 1}

If multiple cracks are present that will remain less than $20 \%$ of the circumference in total length after crack growth, they may be treated as one crack with the length equal to the sum of the lengths.

\section{Case 2}

If multiple cracks are present that will remain less than $30 \%$ of the circumference in total length after crack growth, they may be treated as one crack with the length equal to the sum of the lengths, provided that after crack growth each crack is separated by at least $20 \%$ of the circumference from all other cracks.

\section{Case 3}

All other situations regarding multiple cracks will be considered as a single $360^{\circ}$ crack. 
Case 4

Cracks on both sides of the weld will be treated as if they were all on the side of the weld with the thinnest wall.

\subsection{Weld Overlay Design Criteria}

\subsubsection{Standard Overlay Design}

The standard overlay should be designed to provide a margin of three against limit load failure, assuming that the original pipe were cracked completely through the wall for $360^{\circ}$. The calculation method described in Section 4.1 is acceptable to the staff. Because none of the original weld or heat affected zone is considered in the analysis, the stresses to be used in the analysis depend only on the kind of weld metal used for the overlay. Specifically, if the overlay is made using GTAW or GMAW processes, secondary stress need not be considered.

\subsubsection{Designed Overlays}

In cases where cracks are perpendicular to the weld (axial) or very short in the circumferential direction, even a small amount of overlay will prevent further growth in the length direction, because high compressive stresses are induced at the inner surface of the pipe. In such cases the overlay will also act to prevent leakage.

Weldments with a total length of circumferential cracking less than $10 \%$ of the circumference, with no more than four axial cracks, are considered appropriate for repair by a designed overlay. A standard overlay should be used for more severe cracking.

The thickness of the designed overlay should be at least two layers of weld metal after the surface has passed surface examination by penetrant inspection (PT). If credit is taken for the thickness of the first layer, it must be shown by actual test to contain a minimum of $8 \%$ ferrite, and the original surface must have passed PT.

Because designed overlays take credit for part of the original pipe in their design, there are several ways that the lower toughness of the original fluxed weld may be taken into account. An acceptable design approach is to assume that the crack or cracks requiring the overlay are completely through the original pipe wall for the total length of crack involved. The overlay thickness is calculated so that the asoverlayed cracked weldment meets one of the following requirements:

(a) The IWB 3641 tables in Section XI of the Code, including secondary stress in the calculated stress ratio, or

(b) the staff limit load criterion described in Section 4.1, except that a factor of one for margin on secondary stresses may be used. 
Other approaches to overlay design should be evaluated on a case basis. In general, highly stressed welds should be reinforced with standard overlays.

\subsubsection{Limited Service Overlays}

Overlay designs not meeting the above criteria for either Standard or Designed overlays will be considered suitable for limited service only, not to exceed one fuel cycle of operation.

\subsection{SI Crack Mitigation Criteria}

In general, SI should only be considered to be an appropriate repair for minor cracks. This is because the tip of deep cracks can be in a area of high tensile stress caused by the process, and further crack growth may even be accelerated by the SI treatment. Because the effectiveness of the SI treatment is also related to the applied stress on the weldment, mitigation by SI is not recommended for weldments with service stresses over $1.0 \mathrm{~S}_{\mathrm{m}}$, cracks deeper than $30 \%$ of the wall, circumferential cracking longer than' $10 \%$ of the circumference, and axial cracks of any extent.

Detailed crack sizing, using multiple procedures by examiners qualified for crack sizing, must be carried out after SI. The extent of cracking cannot exceed the limits stated above if the SI is to be considered an acceptable mitigation. 


\subsection{INSPECTONOF PIPING FOR IGSCC UPCO}

\subsection{Weldments Subject to Inspection}

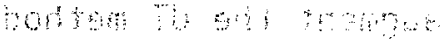

Because cracking of austenttic stainiess stee piping has occurred in essentially at BWR systems, all are considered service sensitive as defined in NURE-0313, Rev 1 .

Weldments subject to the recommendations and staff positions covered by this revision inciude those in al' BWR CTass 1 , 2 , and 3 except those piping systems that never can operate over $200^{\circ} \mathrm{F}$ even with as sumed valve: leakage pipe sizes under 4 inches in nominal diameter are not included.

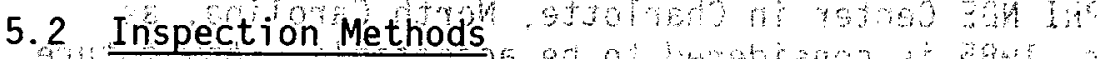

One positive result of the extensive investigations performed on BWR piping is that no significant mode of degradation other than IGSCC has been noted. This means that inspections can focus on those approaches that are best suited for detecting and evaluating IGSCC. A lessfavorable finding is that special methods and specific operator training are required to reliably detect arid characterize IGSCC in the presence of the variable geometric configurations of the weldments.

It is not the intent of this report to provide specific guidance to operators regarding details of equipment and procedures. This function is best handled by Code activittes in which industry and regulatory participants reach a consensus. It is not a simple problem; finding and recognizing IGSCC by UT is stiti as much an art as it is a science. The intent of the recommendations covered by this report is to ensure that the UT operators inspect ing BWR piping for IGSCC can detect and characterize IGSCC in the welds they inspect, and that they will accomplish these two functions retiably the fietd.

\subsubsection{Staff Position on Inspection Methodsand Personne}

The method of examination, volume of materiat to be examined and the al lowable planar indication standards should comply with the requirements set forth in the applicable Edition and Addenda" of the ASME "Code, Section $X I$, specified in paragraph $(\mathrm{g})$, "Inservice Inspection Requirements", of 10 CFR 50.55a, "Codes and Standards". All BWR pipe we d examinations should be performed in accordance with the ultrasonic examination methods and requirements of the latest version A A AME Code Section XI referenced by 10 CFR 50.55a, and the procedure, equipment, and personnel qualified by a formalperformance capablity demonstration test such as that being conducted at EPRI NDE Center in Char otte North Carofina os other combinations of procedure, equipment, and personne may be approved by the NRC on a case-by-case basis. The acceptability of flaw ind ications for continued operation with or without repairs should be determined on the basis of the repair and the analyticat evaluat on procedures and criterion described in part 4.0 of this report. 
Specialized radiographic techniques developed for detection of IGSCC may be used in cases where ultrasonic examination is not practical, or to augment the UT method.

A11 examination procedures and the specific equipment used in the field inspections, and all level 1,2, and 3 NDE examiners or operators for flaw detection and sizing should demonstrate their field performance capability on cracked, preferably service-induced, samples in a manner acceptable to the NRC. No NDE examiner or operator should perform examinations of BWR piping without proving his competence even if he must take special training to gain specific skills and knowledge required to perform these inspections. In accordance with the NDE Coordination Plan agreed upon by NRC, EPRI, and BWROG, the program being conducted at EPRI NDE Center in Charlotte, North Carotina, as upgraded in September, 1985 is considered to be acceptable. Any future changes in this program should be in conformance with the coordination plan and approved by the Executive Director for Operations, NRC.

\subsubsection{Flaw Size Uncertainty}

Inspections performed under IE Bulletins 82-03 and 83-02 were often performed by examiners with limited knowledge and experience in sizing IGSCC. Although the length of the cracks could usually be defined satisfactorily, most UT operators could not determine their throughwall depth accurately and reliably. After this was shown to be true in industry-wide evaluation projects, the industry developed more effective and diverse techniques, and the NDE Center initiated a training and qualification program specifically for crack depth sizing. The NRC staff participated in this effort by defining acceptable levels of performance, based on the level of accuracy required to ensure safe operation. The staff now believes that flaw sizes determined by examiners and procedures qualified by test will not be grossly underestimated or overestimated provided that an adequate design configuration and inspectable weld surface exist.

The depth of cracks not sized by fully qualified personnel or with limitations to examination should be assumed to be at 1 east $75 \%$ of the wall in depth, and the flaw so evaluated.

\subsection{Inspection Frequency}

\subsubsection{Weldment Condition Category Definitions}

The purpose of inservice inspection of piping is to provide continued assurance that the structural integrity and reliability (e.g., see 10 CFR $50.55 \mathrm{a}(\mathrm{g})(6)(\mathrm{ii})$ ) of the piping is maintained, and that there continues to be an extremely low probability of abnormal leakage (10 CFR 50, Appendix A, Criterion 14). Piping with weldments that are susceptible to degradation mechanisms such as IGSCC require more frequent inspections to provide such continued assurance. Weldments in BWRs will 
have different degrees of susceptibility to IGSCC depending on the materials and processing involved. Therefore, the inspection frequencies established by the staff are based on the condition of each weldment. Furthermore, some weldments, such as those involving bi-metallic joints and those connecting pipes to other components such as vessels, pumps, and valves may be more susceptible to cracking by fatigue than other welds. This should also be taken into account in selecting a meaningful inspection program, and has been considered in the staff recommended inspection schedules.

The extent of augmented inspection necessary depends on the number of cracked welds in the plant as well as the condition of each individual weldment. In addition, welds that have already been found to be cracked will have varying degrees of susceptibility to further cracking, depending on the remedial actions taken.

Some may be considered repaired, at least on a conditional basis; whereas, others with marginal or no repair are considered fit for only very limited service without additional action. These seven categories of weldment conditions are defined in detail below.

\subsubsection{Definition of Category A Weldments}

Category $A$ Weldments are those with no known cracks, that have a low probability of incurring IGSCC problems, because they are made entirely of IGSCC resistant materials or have been solution heat treated after welding. CRC is considered to be IGSCC resistant.

\subsubsection{Definition of Category B Weldments}

Category $B$ Weldments are those not made of resistant materials, but have had a SI performed either before service or within two years of operation. If the SI is performed after operation, a UT examination after SI to ensure that they are not cracked is required.

\subsubsection{Definition of Category $C$ Weldments}

Category $C$ Weldments are those not made of resistant materials (see 2.1.1), and have been given an SI process after more than two years of operation. A UT examination to ensure that they are not cracked must be performed after the SI treatment.

\subsubsection{Definition of Category D Weldments}

Category $D$ Weldments are those not made with resistant materials, and have not been given a SI treatment, but have been inspected by examiners and procedures in conformance with section 5.2.1, and found to be free of cracks. 


\subsubsection{Definition of Categóny Weldments}

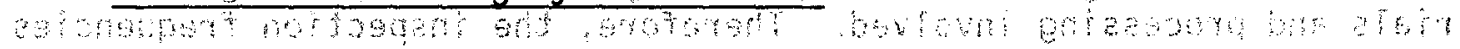

Category E We Tdments are those with known cracks but have been reinforced by an acceptable rweldover lay or have been mitigated by an SI treatment. with subsequent examination ebysqualified examiners and procedures to verify the extent of cracking. Guidelines for acceptable weld overlay reinforcement and extent of cracking considered amenable to SI treatment are covered in Sections 3.2 and 4.5 of this document $900 \%$ and

\subsubsection{Definition of Category $F$ Weldments}

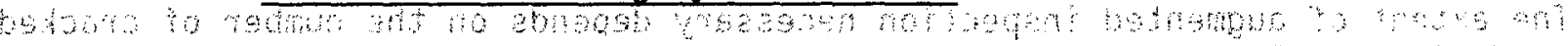

Category $F$ Weldments are those with known cracks ; that have been approved on by analys is for limited additional service without repair. Weldments found to have significant cracking or a questionable extent of cracking thatchave been minimally overlay reinforced (not in conformance with Section 4.1 ) are considered acceptable only for interim operation. Weldments with significant cracking that have been SI treated may also be considered to be in this category: Dêtajled guidelines used to evaluate specific cases are provided in Sections $3: 0$ and $4: 0$ of this document.

\subsubsection{Definition of Category G Weldments}

Category $G$ Weldments are those made of non resistant materials, have not been given an. SI treatment and have not been inspected in accordance with Section 5.2.1. Stress improved welds that were not inspected after the SI treatment are considered to be Category $G$ weldments until the post-SI inspection has been performed.

\subsubsection{Staff Position on Inspection Schedule}

The staff position on the extent and frequency of inspection for various weldments categorized in accordance with 5.3 .1 is discussed in detail below and summarized in Table 2 .

\subsubsection{Inspection Schedule for Category A Weldments}

Category A welds should be inspected according to a schedule similar to that called for in Section XI of the Code: Specifically, resistant bimetallic welds and terminal ends should be inspected every 10 year interval: In addition, a representative sample of $25 \%$ of other welds should be examined every 10 year interval.

\subsubsection{Inspection Schedule for Category B Weldments}

Category $B$ welds are more likely to develop cracking than Category $A$ welds, so a larger sample size is needed. Specifically, Category $B$ bimetallic and terminal end weldments should be inspected every 10 year interval, and in addition, a representative sample of $50 \%$ of other welds should be examined every 10 year interval. 


\subsubsection{Inspection Schedule for Category C Weldments}

Category $C$ welds have longer service life prior to SI than Category $B$ welds, so are more likely to contain undetected cracking. All Category $C$ welds should be inspected within approximately $31 \% 3$ years after the post SI inspection, and again in the next 10 year period.

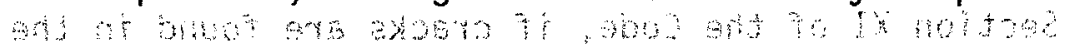

If no cracking is found after this second inspection, weldments may be upgraded to Cátegory B $\mathrm{B}$ th

\subsubsection{Inspection Schedule for Category D Weldments}

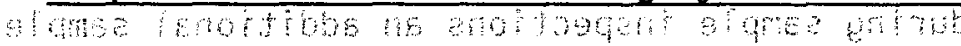

Category 0 Weldments shöulld be inspectéd at least once every $31 / 3$ years Approximately half of the Category D we ldments in the plant should be inspected each refueling outage:

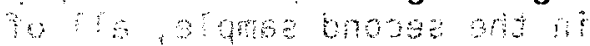

\subsubsection{Inspection Schedule for Category E Weldments}

Repaired and stress improved cracked weldments, Category $E$, should be inspected at least once every inspection period (3-1/3 yrs) after repair. Approximately half of them should be inspected during the first refueling outage after repair.

If it is desired to operate for more than two fuel cycles with overlay reinforcement repairs, the overlayed weldments must be inspected to ensure that the overlays will continue to provide the necessary safety margin. For standard and designed overlays meeting the requirements of Section 4.0, the inspection method must provide positive assurance that cracks have nct progressed into the overlay. It is also desirable that the inspection procedure be capable of detecting cracks that originally were deeper than $75 \%$ of the original wall thickness, or that have grown to be deeper than $75 \%$ of the original wall thickness. Ultrasonic inspections must be performed using a procedure that has been demonstrated to be reliable and effective, and should be performed by personnel that have been trained and qualified in the specific methods for inspections of overlays.

\subsubsection{Inspection Schedule for Category F Weldments}

Category $F$ Weldments are approved for limited service only, and should be inspected every refuel ing outage, unless a shorter service period has been specified.

\subsubsection{Inspection Schedule for Category G We Idments}

Category $G$ Weldments should be inspected at the next refueling outage.

\subsubsection{Inspection Schedules with HWC}

If improved water chemistry control, including hydrogen additions is implemented, the time schedule for inspections may be extended. Although specific details of such extensions will be evaluated on a case basis, it is anticipated that periods between inspections could be lengthened by about a factor of two for category B, C, D and E weldments. 


\subsubsection{Sample Expansion Method}

As is required by Section XI of the Code, if cracks are found in the sample being inspected, an additional sample must be inspected. For inspections performed under this program, the following logic should be used.

If cracks are found during sample inspections an additional sample approximately equal in number to the initial sample should be examined. This second sample should be selected from other weld of the same inspection category and welds of lower categories irrespective of pipe size or system. If any cracks are found in the second sample, all of the welds in that category and lower categories should be inspected. 
TABLE 2

\begin{tabular}{llll} 
DESCRIPTION OF WELDMENTS & NOTES & $\begin{array}{l}\text { IGSCC } \\
\text { CATEGORY }\end{array}$ & $\begin{array}{c}\text { INSPECTION } \\
\text { EXTENT \& SCHEDULE }\end{array}$ \\
\hline Resistant Materials & A & All Bimetallic every 10 yrs \\
& & All terminal ends every 10 yrs \\
& & $25 \%$ of other welds every 10 yrs
\end{tabular}

\begin{tabular}{|c|c|c|}
\hline $\begin{array}{l}\text { Nonresistant Matls } \\
\text { SI within } 2 \text { yrs of } \\
\text { Operation (1) }\end{array}$ & (1) & $\begin{array}{l}\text { A11 Bimetal1ic every } 10 \text { yrs } \\
\text { A11 Terminal Ends every } 10 \text { yrs } \\
50 \% \text { others every } 10 \text { yrs }\end{array}$ \\
\hline
\end{tabular}

Nonresistant Matis

SI after 2 yrs of

Operation (1)
(1)

1) C

A11

then:

A11 next $31 / 3$ yrs

next 10 yrs
Non Resistant Matl

No SI

Cracked
overlayed or SI (1)(2)

Cracked

Inadequate or

No Repair (2) $\begin{array}{llll} & & & \end{array}$

(1)(2) E

A11

then:

A11 every $31 / 3$ yrs

next outage

Non Resistant

Not Inspected (3)

(2)

A11

every outage

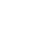




\section{0 LEAK DETECTION}

The reactor coolant leakage detection systems should be operated under the Technical Specification requirements to enhance the discovery of unidentified leakage that may include through-wall cracks developed in austenitic stainless steel piping.

(1) The leakage detection system should include sufficiently diverse leak detection methods with adequate sensitivity to ensure the detection of small leaks in a timely manner and to identify the leakage sources within practical limits. Acceptable leakage detection and monitoring systens are described in Position C of Regulatory Guide 1.45, "Reactor Coolant Pressure Boundary Leakage Detection Systems."

Particular attention should be given to upgrading and calibrating those leak detection systems that will provide prompt indication of an increase in leakage rate.

Other equivalent leakage detection and collection systems will be reviewed on a case-by-case basis.

(2) Plant shutdown should be initiated for inspection and corrective action when any leakage detection system indicates, within a period of 24 hours or less, an increase in rate of unidentified leakage in excess of $2 \mathrm{gpm}$ or its equivalent, or when the total unidentified leakage attains a rate of $5 \mathrm{gpm}$ or its equivalent, whichever occurs first. For sump level monitoring systems with fixed-measurement interval method, the level should be monitored at 4-hour intervals or less.

(3) Unidentified leakage should include all leakage other than

(a) leakage into closed systems, such as pump seal or valve packing leaks that are captured, flow metered, and conducted to a sump or collecting tank, or

(b) leakage into the containment atmosphere from sources that are both specifically located and known either not to interfere with the operations of unidentified leakage montoring systems or not to be from a throughwall crack in the piping within the reactor coolant pressure boundary. 


\section{APPENDIX A - CRACK GROWTH CALCULATIONS}

\section{Introduction}

Crack growth calculations are required to evaluate the continued structural integrity of a weld with known cracks, if it is desired to continue operiation without repair or reinforcement. The rate of growth of IGSCC is not easy to predict, because the several important factors are usually imperfectly known. Research work in this area has been helpful in defining the general effect of these factors, but a large uncertainty in crack growth predictions still remain.

Nevertheless, crack growth calculations can be performed within certain limits with enough confidence to ensure plant safety without excessive conservatism.

Crack growth calculations are based on the fundamental concept that the crack growth rate of a specific material in a specific environment will be a function of the applied stress intensity factor, $\mathrm{K}_{\mathrm{I}}$. Laboratory crack growth data are usually presented in this manner. Details of the calculational methods used to calculate $K_{1}$ are provided later in this Appendix, but an important point to note here is that $k_{\text {I }}$ depends on the crack depth, therefore it changes continuously during crâck growth.

Crack growth analysis methods are, therefore, iterative in nature. Given an initial crack depth, the $K_{I}$ is calculated for the particular stress distribution of interest. Knowing the $k$, the amount of growth for a specific time is calculated, the growth is added to the initial crack depth, a new $K_{I}$ is calculated, and the process is repeated. Time intervals selected can vary from 1 hour to 1000 hours, depending on the rate of growth and rate of change in $K_{I}$ with crack depth.

\section{Selection of Crack Growth Rate Parameters}

Although only two parameters, crack growth rate and $\mathrm{K}_{I}$, are used, they are both highly dependent on several factors.

Crack growth rate is affected by the degree of sensitization of the material and by the severity of the environment. Our interest as it relates to BWR piping is primarily in a degree of sensitization normally caused by welding, and in an environment similar to normal BWR water conditions.

Most formal crack growth studies are carried out with standard fracture mechanics specimens, which makes $K_{1}$ determination easy. These specimens are not readily machined from pipe welds, so the material is given an artificial sensitization treatment; intended either to simulate the effect of welding or, in some cases, the more severe effect of furnace sensitization. Tests to ascertain whether the intended degree of sensitization has been obtained are still inexact, causing significant scatter in laboratory test results intended to apply to a similar metaliurgical state. 
Tests to simulate the BWR environment are usually run at operating temperature in high purity water containing $0.2 \mathrm{ppm}$ oxygen. This is generally accepted to be a representative condition, although higher oxygen levels could occur locally for short periods of time. Tests are also often run in water containing up to $8 \mathrm{ppm}$ oxygen, usually to achieve accelerated comparisons of materials or conditions.

In addition to these standardized tests for crack growth rate, results of actual pipe tests are available. Many hundreds of welds have been tested in General Electric's pipe test facility. These tests, although generally more relevant in terms of material condition and environment, are more difficult to evaluate. $K_{I}$ is more difficult to calculate, and accurate crack growth rates are also more difficult to measure. Nevertheless, this body of data has been used to augment those data from the more standard laboratory tests, to select appropriate crack growth rates.

Figure 1 (from NUREG/CR-3292) * shows much of the relevant laboratory data in the conventional form, where measured rates are plotted against $K_{I}$. This plot clearly shows the large scatter resulting from a wide variation in material condition and environment. This information, together with additional information from actual pipe tests, was used to select a crack growth curve that is appropriate for use in safety evaluations. Note that if the fastest crack growth rate shown in Figure 1 is used, cracks would be predicted to grow completely through pipe walls in a matter of days. Clearly this would not reasonably represent reality.

The curve selected for use by the NRC staff is shown on Figure 2. Note that it is a curved line on the semilogarithmic chart. On log-log coordinates, it plots as a straight line. In calculations, it is expressed as:

$$
\mathrm{da} / \mathrm{dt}=3.590 \times 10^{-8} \cdot \mathrm{K}_{\mathrm{I}}^{2.161} \text { inches per hour }
$$

As can be seen, the crack growth rate is a very strong function of $K_{I}$. In laboratory tests, $K_{I}$ is easily determined with good accuracy. This is not the case for real pipes and real pipe cracks. There are two major sources of uncertainty: knowledge of the actual crack size and shape, and the actual stress distribution in the area of the crack to be evaluated. The service distribution at a pipe weld is made up of the stress caused by the service loading and the residual stresses caused by the welding process. Of these, knowledge of the residual stress is the more uncertain. Nevertheless, a residual stress distribution through the pipe wall must be defined, if realistic crack growths are to be calculated. Although this is covered later in more detail, several comments are in order here.

The residual stress distribution caused by welding is the major stress component causing IGSCC. Welding causes a high tensile residual stress on the inside surface of the pipe near the root of the weld where the material is sensitized.

* Shack, W.J., et al., "Environmentally assisted cracking in light water Water Reactors: Annual Report, October 1981 - September $1982^{11}$

NUREG/CR-3292, Washington, DC: U.S. Nuclear Regulatory Commission, February, 1983. 
This residual stress level has been calculated and measured to be up to or above the yield strength of the material. It typicaliy is four or five times as high as the service-induced stress. In fact, without this very high residual stress at the sensitized area, IGSCC would not be a problem in BWR piping. This fundamental observation is helpful; wherever this combination of stress and sensitization occurs, cracking occurs. In actual cases, if there are significant cracks, there must be significant tensile residual stresses, and this should be accounted for in the crack growth analysis. The method used by the staff is described below.

\section{Stress Intensity Factor Calculations}

There are several relatively standard analytical solutions available for calculating the stress intensity factor $\left(K_{I}\right)$ caused by stress distributions of the type found at BWR pipe welds. The method using influence functions is the one used by the staff and will be summarized here. Other methods, such as those described in the ASME Boiler and Pressure Vessel Code, Section XI, Appendix A, may also be used where appropriate.

\section{Stress Analysis}

The total stress state, including residual stress, pressure stress, and other stresses caused by normal operation must be known or assumed. Note that factors such as stress indices used for purposes of other stresses should not be used when calculating stress levels that apply to $K_{I}$ calculations.

\section{$\underline{\text { Residual Stress }}$}

The laboratory-measured throughwall axial residual stresses on pipe wall thickness $\geq 1$ inch are presented in Figure 3 (from NUREG/CR-3292). The solid line in Figure 3 is the axial residual stress distribution used for the calculation of stress intensity factors for pipe sizes of 12" diameter and larger. The residual stress distribution is the most complex analytical problem involved. This is handled by fitting the curve of residual stress distribution through the wall by an analytical expression. For this particular residual stress distribution, the nondimensional expression given below is used.

where

$$
\sigma / \sigma_{i}=\sum_{j=0}^{4} \sigma_{j} \xi^{j}
$$

$$
\begin{aligned}
\sigma_{0} & =1.0 \\
\sigma_{1} & =-6.910 \\
\sigma_{2} & =8.687 \\
\sigma_{3} & =-0.480 \\
\sigma_{4} & =-2.027 \\
\xi & =x / t \\
\sigma_{i} & =\text { stress magnitude at } \xi=0 \text { (inner surface) } \\
& -A .3-
\end{aligned}
$$


The above formula permits calculation of the residual stress value at any point $(x)$ through the vessel wall thickness $(t)$ as a function of the peak residual stress value at the inside diameter (ID), $\sigma_{i}$.

The stress intensity factor caused by the residual stress from welding ( $\left.K_{I R}\right)$, is calculated using influence functions taken from NUREG CR-3384, * page A. 19 , Table (7). The influence functions, $i_{j}$, given in this Appendix are for a $360^{\circ}$ circumferential crack in a cylinder with a $R / t$ ratio of 10 . In view of other analytical conservatisms and uncertainties (i.e., assumed crack geometry and initial depths), it is believed that they may be used for cylinders with $R / t$ ratios of from 9 to 11 to obtain reasonable and conservative estimates of crack growth versus time. For $R / t$ ratios significantly different from 10, other influence functions or other analytical methods should be used.

The specific formula used by the staff is:

$$
K_{I R} /\left(\sigma_{i} \sqrt{t}\right)=\sqrt{\pi \alpha} \sum_{j=0}^{4} \sigma_{j} \alpha^{j} i_{j}
$$

where:

\section{Membrane Stress}

$$
\begin{aligned}
& \sigma_{0}, \ldots \sigma_{4} \text { and } \sigma_{i} \text { are as above } \\
& i_{0}=1.1220+0.3989 \alpha+1.5778 \alpha^{2}+0.6049 \alpha^{3} \\
& i_{1}=0.6830+0.1150 \alpha+0.7556 \alpha_{2}{ }^{2}+0.1667 \alpha_{3} \\
& i_{2}=0.5260+0.1911 \alpha-0.1000 \alpha_{2}+0.5802 \alpha_{3} \\
& i_{3}=0.4450+0.0783 \alpha+0.0556 \alpha_{2}+0.3148 \alpha_{3}{ }_{3} \\
& i_{4}=0.3880+0.1150 \alpha-0.1333 \alpha^{2}+0.3519 \alpha^{3} \\
& \alpha=a / t \\
& \mathrm{a}=\text { crack depth } \\
& t=\text { wall thickness }
\end{aligned}
$$

The membrane stresses are assumed constant through the wall thickness, so

$$
\sigma_{m}=\sigma_{p}
$$

where

$$
\sigma_{p}=\text { membrane stress }\left(\sigma_{m}\right) \text { from pressure }
$$

\footnotetext{
* Stevens, D.L., et a1., "VISA-A Computer Code for Predicting the Probability of Reactor Vessel Failure" NUREG/CR-3384 PNL-4774, Washington, DC. U.S. Nuclear Regulatory Commision, September, 1983.
} 
The stress intensity factor for a $360^{\circ}$ circumferential crack from pressure, $\mathrm{K}_{\mathrm{IP}}$, is calculated by

$$
K_{I P}=(P R / 2 t) \sqrt{t} \quad \sqrt{\pi \alpha}\left(1.122+0.3989 \alpha+1.5778 \alpha^{2}+0.6049 \alpha^{3}\right)
$$

where

$$
\begin{aligned}
& \alpha, t \text { are as above } \\
& P=\text { pressure } \\
& R=\text { radius to center of pipe wall }
\end{aligned}
$$

The total stress intensity factor, $K_{I T}$, is given by

$$
K_{I T}=K_{I P}+K_{I R}
$$

where

$$
K_{I P} \text { and } K_{I R} \text { are defined as above. }
$$

\section{Correlation with Service Experience}

Although the residual stress is assumed to be the same for all welds, the applied stresses, primary and secondary, vary from weld to weld; therefore, calculations must be performed for each weld evaluated. Figure 4 shows the results of $K_{I}$ calculations for several pipe sizes using a nominal applied stress of $7500 \mathrm{psi}$. Note that at relatively shallow depths, the $K_{I}$ is high; therefore, the crack growth rate will be relatively fast. However, the $K$ actually diminishes as the crack grows to about half way through the wall. This prediction is consistent with service experience; very few, if any, actual cracks of significant circumferential extent have been found deeper than about $50 \%$ of the wall thickness. 


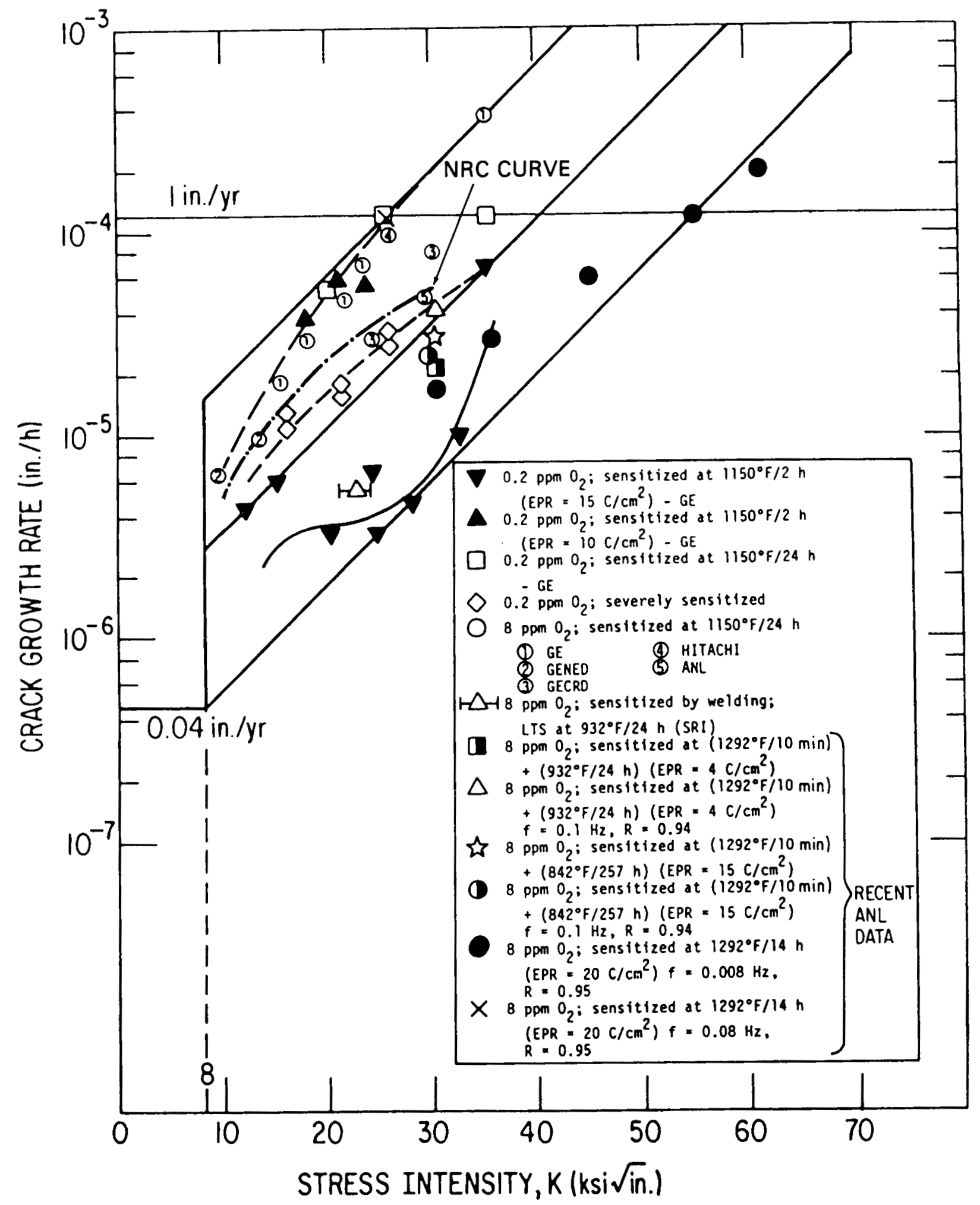

Fig. 1 CRACK GROWTH RATE DATA

A. 6 


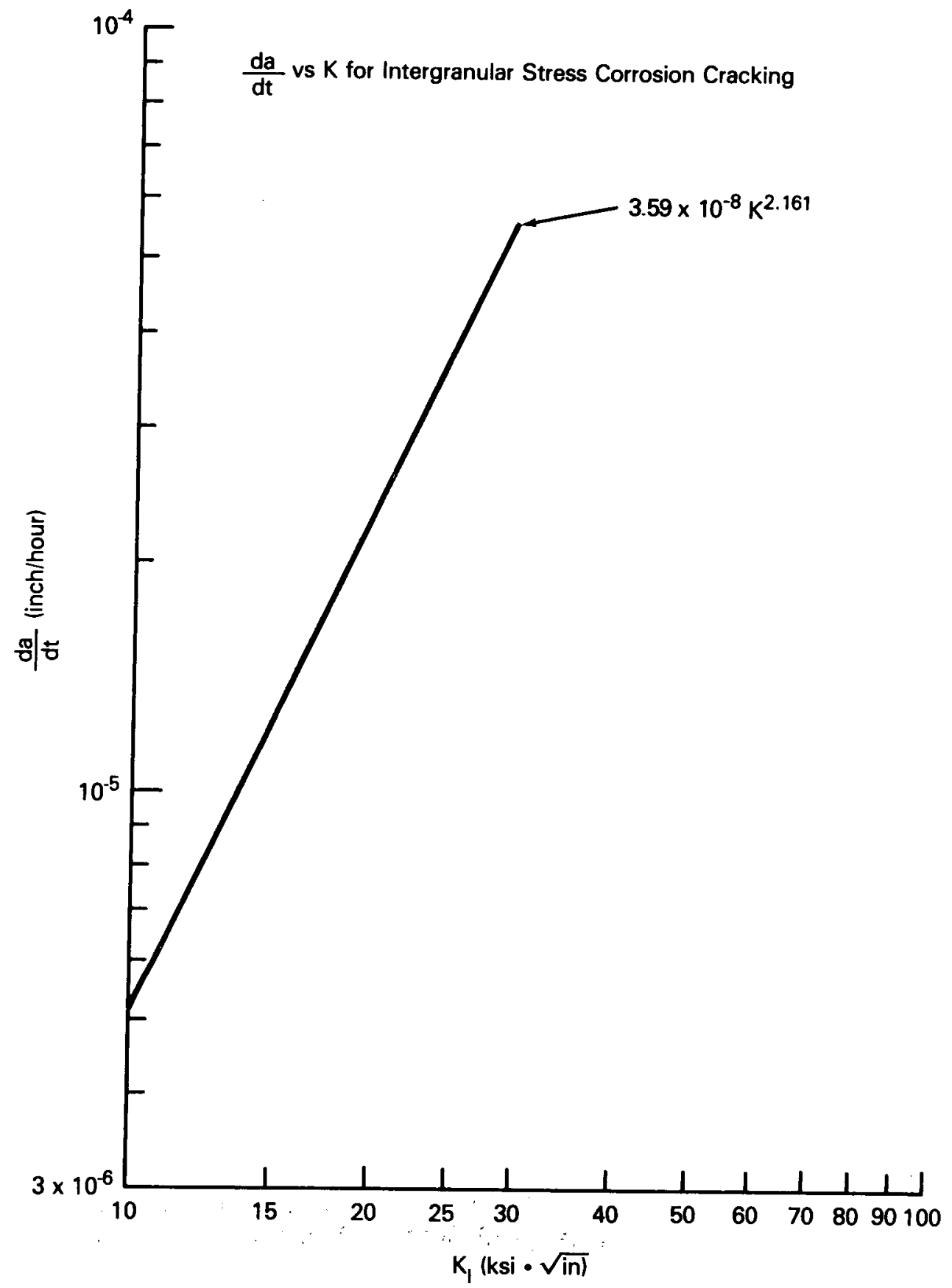

Figure 2

$\frac{d a}{d t}$ vs $K$ for Intergranular Stress Corrosion Cracking

A. 7 


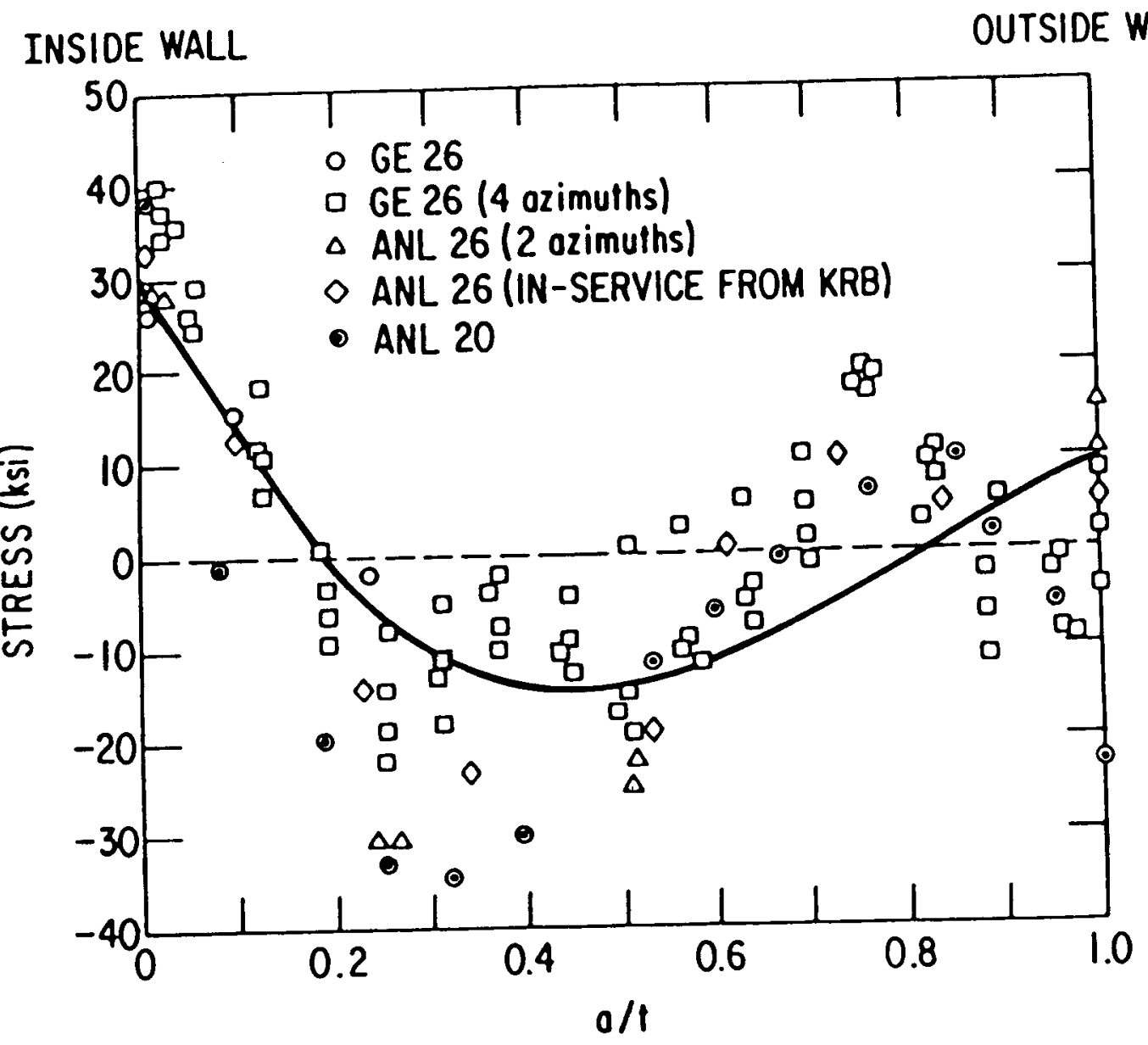

Fig. 3 Through-wall Distribution of Axial Residual Stress in Large-Diameter Pipes ( $t \geq 1$ in.).

A. 8 


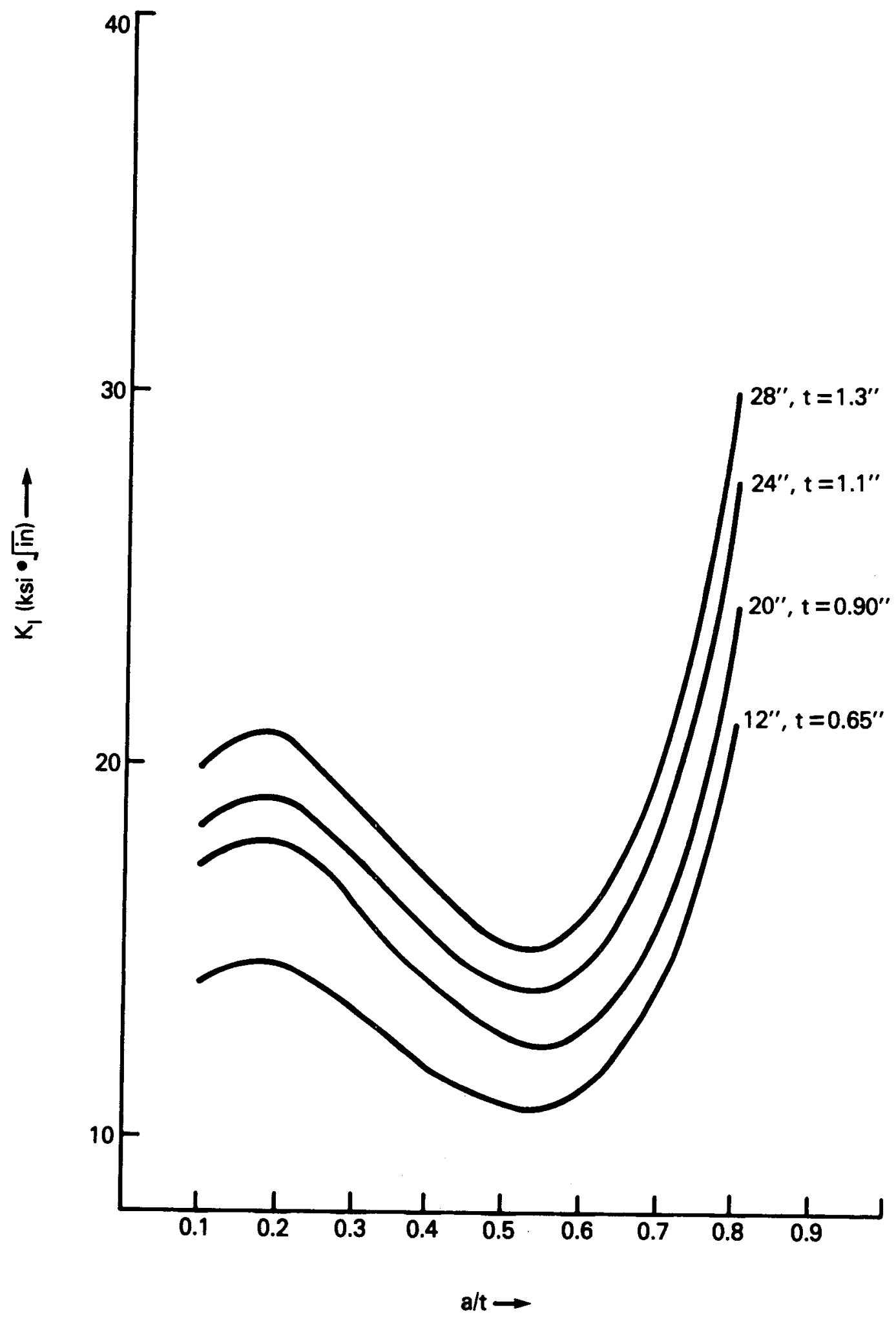

Figure 4

THROUGH-WALL DISTRIBUTION OF $K_{I}$ WITH APPLIED STRESS OF 7500 PSI

A. 9 


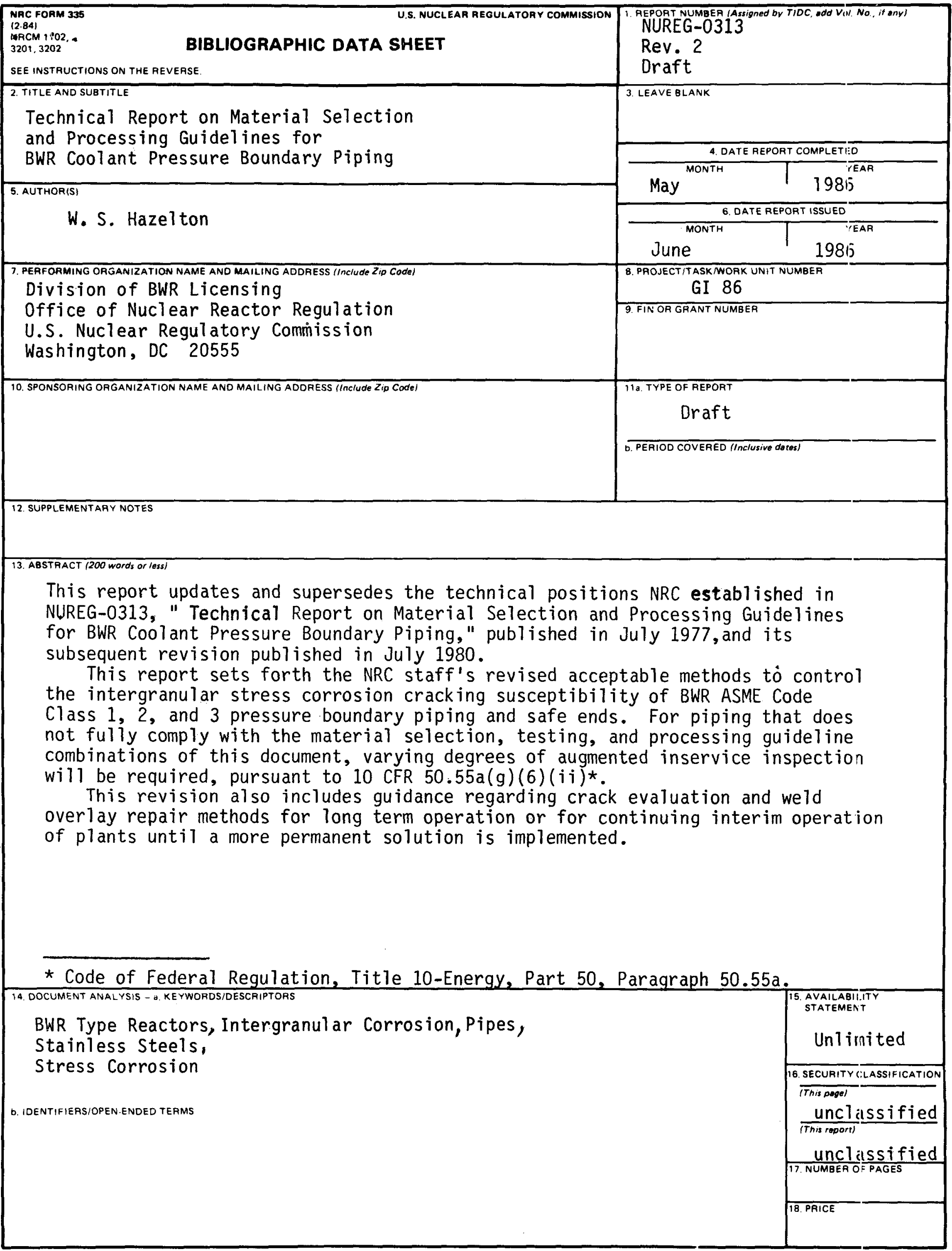

